Article

\title{
Theoretical in-Solution Conformational/Tautomeric Analyses for Chain Systems with Conjugated Double Bonds Involving Nitrogen(s)
}

\author{
Peter I. Nagy
}

Center for Drug Design and Development, the University of Toledo, Toledo, OH 43606, USA;

E-Mail: pnagy@utnet.utoledo.edu; Tel.: +1-419-530-2167; Fax: +1-419-530-7946

Academic Editor: Malcolm D'Souza

Received: 16 March 2015 / Accepted: 5 May 2015 / Published: 13 May 2015

\begin{abstract}
Conformational/tautomeric transformations for $\mathrm{X}=\mathrm{CH}-\mathrm{CH}=\mathrm{Y}$ structures $\left(\mathrm{X}=\mathrm{CH}_{2}, \mathrm{O}, \mathrm{NH}\right.$ and $\mathrm{Y}=\mathrm{NH}$ ) have been studied in the gas phase, in dichloromethane and in aqueous solutions. The paper is a continuation of a former study where $s$-cis/s-trans conformational equilibria were predicted for analogues. The s-trans conformation is preferred for the present molecules in the gas phase on the basis of its lowest internal free energy as calculated at the B97D/aug-cc-pvqz and $\operatorname{CCSD}(\mathrm{T})_{\mathrm{CBS}}$ (coupled-cluster singles and doubles with non-iterative triples extrapolated to the complete basis set) levels. Transition state barriers are of $29-36 \mathrm{~kJ} / \mathrm{mol}$ for rotations about the central $\mathrm{C}-\mathrm{C}$ bonds. In solution, an s-trans form is still favored on the basis of its considerably lower internal free energy compared with the $s$-cis forms as calculated by IEF-PCM (integral-equation formalism of the polarizable continuum dielectric solvent model) at the theoretical levels indicated. A tetrahydrate model in the supermolecule/continuum approach helped explore the 2solute-solvent hydrogen bond pattern. The calculated transition state barrier for rotation about the $\mathrm{C}-\mathrm{C}$ bond decreased to $27 \mathrm{~kJ} / \mathrm{mol}$ for the tetrahydrate. Considering explicit solvent models, relative solvation free energies were calculated by means of the free energy perturbation method through Monte Carlo simulations. These calculated values differ remarkably from those by the PCM approach in aqueous solution, nonetheless the same prevalent conformation was predicted by the two methods. Aqueous solution structure-characteristics were determined by Monte Carlo. Equilibration of conformers/tautomers through water-assisted double proton-relay is discussed. This mechanism is not viable, however, in non-protic solvents where the calculated potential of mean force curve does not predict remarkable solute dimerization and subsequent favorable orientation.
\end{abstract}


Keywords: s-cis/s-trans equilibrium; IEF-PCM/B97D/aug-cc-pvqz; IEF-PCM/CCSD(T)/ CBS; FEP/MC; tautomerization mechanism

\section{Introduction}

In a recent publication [1], the conformations of a chain with conjugated double bonds, called double bond-single bond-double bond (DSD) systems, were studied in the gas phase and in different solvents. The central moiety of these structures is the $\mathrm{X}=\mathrm{C}-\mathrm{C}=\mathrm{Y}$ fragment, and different combinations of the $\mathrm{CH}_{2}$ and $\mathrm{O}$ groups for $\mathrm{X}$ and $\mathrm{Y}$ were investigated previously. The $\mathrm{CH}_{2}, \mathrm{O}$ and $\mathrm{NH}$ groups are, however, isoelectronic and can replace each other as $\mathrm{X}$ and $\mathrm{Y}$. The scientific aim of the present paper is the structural analysis when one or two NH groups appear in a DSD molecule. For such systems, an $s$-trans $/ s$-cis conformational equilibrium is possible, corresponding to $\mathrm{XCCY}=180^{\circ}$ and $0^{\circ}$, respectively, in combination with the $\mathrm{CC}=\mathrm{NH}$ anti and syn arrangements. All structures (Schemes 1 and 2) have been investigated accordingly.

The $\mathrm{R}_{1}-\mathrm{CH}=\mathrm{N}-\mathrm{R}_{2}$ structure is the typical subunit in Schiff-bases. If $\mathrm{R}_{1}$ contains a double bond in possible conjugation with the indicated $\mathrm{C}=\mathrm{N}$ double bond, $s$-cis/s-trans conformational equilibrium may be expected. This structural peculiarity was demonstrated by Houjou et al. for the Schiff bases of double-headed, fused salicylaldehydes [2]. For preparing unsaturated Schiff bases, Sammour et al. [3] found that the $\mathrm{C}=\mathrm{C}-\mathrm{C}=\mathrm{N}$ substructure is favorable for Michael-type condensation for ring closure, which requires the $\mathrm{CCCN} s$-cis conformation. The same substructure appears in an $\alpha, \beta$-unsaturated Schiff base, 1-(CH=N-R) cyclohexene, where the hydrolysis mechanism and reaction rate may depend on the conformation of the $\mathrm{C}=\mathrm{C}-\mathrm{C}=\mathrm{N}$ moiety [4].

Complexes of $\mathrm{Ni}$ and $\mathrm{Pd}$ with $\alpha$-diimine derivatives, including the $\mathrm{N}=\mathrm{C}-\mathrm{C}=\mathrm{N}$ substructure have turned out to be important late-metal catalysts for ethylene homo- and co-polymerization [5]. Prerequisite to the complex formation is the $s$-cis conformation of the $\alpha$-diimine. Conformational analysis for such DSD molecules in solution can be found only rarely in the literature. Exner and Kliegman [6], and references there studied the in-solution conformation equilibrium for $\mathrm{RN}=\mathrm{CH}-\mathrm{CH}=\mathrm{NR}$ molecules based on bond moments. The predicted bond moments are questionable, however, in the absence of precise molecular geometries and for the present species with interacting electrons of two $\pi$-bonds separated by a formal single bond. Furthermore, bulky R substituents may affect the equilibrium composition. For example, substituted $N, N^{\prime}$-diphenyl $\alpha$-diimines were studied in [6], where the two benzene rings could favorably interact in the s-cis conformation, resulting in additional stability of the conformer not present for the unsubstituted diimine. Thus a high-level quantum chemical study based on in-solution optimized geometries is justified for a possibly better interpretation of the experimental findings. Considering [1] as well, the obtained results are novel on the field of the in-solution conformational analysis for DSD molecules with any combination of the $\mathrm{CH}_{2}, \mathrm{O}$ and $\mathrm{NH}$ groups.

In the case when $\mathrm{X}$ and/or $\mathrm{Y}$ correspond(s) to $\mathrm{NH}$, the conformational variability can be combined with tautomeric isomerization through ketene amine/aldimine and imino-ketene amine/diimine transformations. No theoretical study of the related structural problems, considering also the solvent 
effects for identifying the most stable conformer/tautomer for a given composition, has been found in the literature either.

Schemes 1 and 2 show isomeric $\mathrm{C}_{3} \mathrm{H}_{5} \mathrm{~N}, \mathrm{C}_{2} \mathrm{H}_{3} \mathrm{NO}$ and $\mathrm{C}_{2} \mathrm{H}_{4} \mathrm{~N}_{2}$ structures. Following the ChemSpider (Available online: http://www.chemspider.com) free online chemical structure database, structures (1), (5), and (10) were identified. In general, this database provides experimental and theoretically calculated values of properties for molecules. For species (1), (5), and (10), however, no experimental in-solution data were available, their partition coefficients, basicities, etc. were only calculated by means of physical- chemical parameter-predicting softwares.<smiles>C=CC=N</smiles>

1 tA<smiles>C=CC=N</smiles>

$3 \mathrm{cA}$<smiles>N=CC=O</smiles>

$5 \mathrm{tA}$

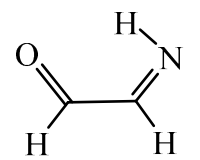

$7 \mathrm{cS}$<smiles></smiles>

2 tS<smiles></smiles>

$4 \mathrm{cS}$<smiles>N=CC=O</smiles>

$6 \mathrm{tS}$<smiles>N=CC=O</smiles>

$8 \mathrm{cA}$<smiles>[NH]NC=C=O</smiles>

9

Scheme 1. 2-Propene-1-imine (1-4); 2-imino acetaldehyde (5-8); 2-amino ketene (9). Letters $\mathrm{t}$ and $\mathrm{c}$ stand for the $s$-trans and s-cis conformations, respectively, letters $\mathrm{A}$ and $\mathrm{S}$ stand for $\mathrm{CCNH}$ anti and syn orientations respectively. The heavy atoms are nearly or entirely coplanar. Remarkable deviation from planarity was found for structure (9). For detailed geometric data, see Supplementary Information (Table S1 and Figure S1a-d). 
Thus stable, in-solution species are probably not known experimentally for these simple DSD structures, although the interest toward the prediction of their physical-chemical properties strongly suggests that the molecules are on the horizon of drug-design companies. A structurally related problem emerges for the drugs Nexium and Protonix, where the $\mathrm{O}=\mathrm{S}-\mathrm{C}=\mathrm{N}$ substructure appears. The $s$-cis/s-trans equilibrium of the two double bonds may influence their biological effect [7].

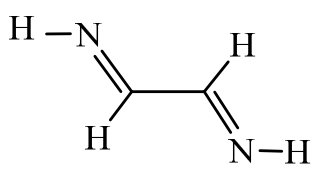

10 tAA<smiles></smiles>

12 tSS<smiles></smiles>

$14 \mathrm{cSS}$

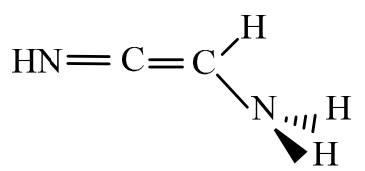

16<smiles></smiles>

$11 \mathrm{tAS}=\mathrm{tSA}$<smiles></smiles>

$13 \mathrm{cAS}=\mathrm{cSA}$<smiles></smiles>

$15 \mathrm{cAA}$<smiles>NC#CN</smiles>

17

Scheme 2. 1,2-Ethane diimine (10-15); 2-amino imino-ketene (16); 1,2-diamino acetylene (17). For t, c, A and S codes, see Scheme 1. The heavy atoms are nearly or entirely coplanar. Remarkable deviations from planarity was found for structures (16) and (17). For detailed geometric data, see Supplementary Information (Table S1 and Figure S1a-d).

Since a double-bonded $\mathrm{sp}^{2}$ nitrogen bears an in-plane lone pair that can isomerize with the single-bonded group connecting to the nitrogen, the structural variability is even larger. The syn and anti conformations of oximes $\left(\mathrm{R}_{1} \mathrm{C}\left(\mathrm{R}_{2}\right)=\mathrm{N}-\mathrm{OH}\right.$ could isomerize by nitrogen inversion (the lone pair and the $\mathrm{N}-\mathrm{O}$ bond formally switch), although the reaction path was found to demand activation energy of as large as about $250 \mathrm{~kJ} / \mathrm{mol}$ in the gas-phase on the basis of $6-31 \mathrm{G}$ calculations [8]. However, isomerization activation energy in solution may be much smaller upon some catalytic effect of the 
solvent having both hydrogen-bond donor and acceptor sites $[9,10]$. The role of the catalytic water through the keto-iminol tautomerization of related hydroxamic acids was clearly demonstrated by Guruge and Dissanayake [11].

Recently Allen and Tidwell [12] presented a review with a large number of chemical reactions for the formation of substituted ketenes and imino-ketenes. Although structures (9) and (16) were not found among them, the reactions may be successfully applied for their formations, too. 1,2-Diamino acetylene, $\mathrm{H}_{2} \mathrm{~N}-\mathrm{C} \equiv \mathrm{C}-\mathrm{NH}_{2}(17)$ can tautomerize first to a cumulene structure of $\mathrm{NH}=\mathrm{C}=\mathrm{CH}-\mathrm{NH}_{2}(16)$, and can move on, in a further step, to the DSD form of $\mathrm{HN}=\mathrm{CH}-\mathrm{CH}=\mathrm{NH}$ (10).

Tautomeric transformations through intramolecular pathways are unlikely for the present target molecules for steric reasons. If tautomerization appears in the gas phase at all, the process can take place probably along a complicated path by means of intermolecular interactions. In-solution structural studies for small molecules have been the subject of theoretical investigations for a long time, e.g., [13-25]. The present paper fits in the series of studying 1,2 disubstituted ethanes [1,16,18,22-24] in solution. For substructures with possibly interacting, nearby hydrogen-bonding sites, special molecular mechanics parameterization is needed in order to satisfy demands emerging, for example, through theoretical drug design. The main goal of the present paper is to determine the free energy differences for the structural isomers (conformers/tautomers) of N-containing DSD molecules in solution and providing a clue about the involvement of the solvent in the equilibration process. To this latter aim, supermolecules were investigated in some cases when the continuum solvent approach was applied, and explicit solvent Monte Carlo simulations were performed.

An investigation for a small system allows for the application of high-level theoretical calculations, thus facilitates the exploration of the effects of the applied theoretical level on the results. Accordingly, large-basis-set DFT/B97D [26] relative free energies were calculated for all investigated pairs of conformers/tautomers in the present paper, and the results were compared with the CCSD(T) relative internal energies (coupled-cluster singles and doubles with non-iterative triples $[27,28]$ ) at its complete basis set limit in many cases. Former studies $[1,23]$ proved that the IEF-PCM relative solvation free energies, calculated for energy-minimized structures, could remarkably differ from those calculated by the free energy perturbation method utilized in Monte Carlo (FEP/MC) simulations. For comparison, FEP/MC values were also calculated here for several isomeric pairs in dichloromethane and/or in water. This latter type of calculations provides means to characterize the first solvation sphere of the solutes and help explore the thermally averaged possible solute-solvent hydrogen-bond structure.

\section{Results and Discussions}

\subsection{Gas Phase}

Gas-phase energy results are provided in Table 1. Although some of the structures in Schemes 1 and 2 are rather peculiar, all of them have turned out to form local-minimum-energy tautomers/conformers on the basis of quantum chemical calculations.

The s-trans/anti form for 2-propene-1-imine (1) is more stable in free energy, $\Delta \mathrm{E}^{\mathrm{g}} \mathrm{int}+\Delta \mathrm{G}^{\mathrm{g}}$ (hee Section 3), by $11.0 \mathrm{~kJ} / \mathrm{mol}$ than the s-cis/anti (3) conformation, as calculated at the B97D level. Penn [29] recorded the gas-phase microwave spectrum for this molecule and found only the s-trans 
conformer. An s-trans to s-cis conformational change requires the rotation about the central $\mathrm{C}-\mathrm{C}$ bond. The torsion barrier for (1) to (3) is $29-36 \mathrm{~kJ} / \mathrm{mol}$ at the two theoretical levels (Table 1) with very similar transition state $\mathrm{CCCN}$ torsion angles of $95.4^{\circ}$ and $96.1^{\circ}$. Although the molecules could acquire the calculated activation energy upon collision for a gas-phase transformation, the experimental result for the lack of the s-cis conformer is in good accord with the B97D relative free energy or the calculated $\operatorname{CCSD}(\mathrm{T})_{\mathrm{CBS}}$ activation energy of $11.4 \mathrm{~kJ} / \mathrm{mol}$ (the B97D and MP2 $\Delta \mathrm{G}^{\mathrm{g}}$ th values could be taken as similar, as revealed from the specifically calculated MP2 values for species (11), see below, thus an estimate for the $\operatorname{CCSD}(\mathrm{T})_{\mathrm{CBS}}$ relative free energy is $9 \mathrm{~kJ} / \mathrm{mol}$, still too high).

Table 1. Relative energy/free energy components for tautomeric/conformational isomers ${ }^{\mathrm{a}}$.

\begin{tabular}{|c|c|c|c|c|c|c|c|c|}
\hline \multirow{2}{*}{ Structures in Schemes } & \multicolumn{2}{|c|}{ Gas } & \multicolumn{3}{|c|}{ Dichloromethane } & \multicolumn{3}{|c|}{ Water } \\
\hline & $\Delta \mathbf{E}_{\text {int }}^{\mathbf{g}_{1}}$ & $\Delta \mathbf{G}_{\text {th }}^{\mathbf{g}}$ & $\Delta \mathbf{E}_{\mathrm{int}}^{\mathbf{s}_{\mathrm{f}}}$ & $\Delta \mathbf{G}_{\text {th }}^{\mathrm{s}}$ & $\Delta \mathbf{G}_{\text {solv }}$ & $\Delta \mathbf{E}_{\mathrm{int}}^{\mathbf{s}_{\mathrm{f}}}$ & $\Delta \mathbf{G}_{\text {th }}^{\mathbf{s}}$ & $\Delta \mathbf{G}_{\text {solv }}$ \\
\hline $\mathrm{CH}_{2}=\mathrm{CH}-\mathrm{CH}=\mathrm{NH}(\mathbf{1})$ & 0.0 & 0.0 & 0.0 & 0.0 & 0.0 & 0.0 & 0.0 & 0.0 \\
\hline $\operatorname{TS}(\mathbf{1}$ to $\mathbf{2})$ & $\begin{array}{c}113.9 \\
123.2^{\mathrm{c}}\end{array}$ & $-9.9^{b}$ & 111.5 & $-10.1^{b}$ & 7.8 & 110.3 & $-10.3^{b}$ & 10.3 \\
\hline $\mathrm{CH}_{2}=\mathrm{CH}-\mathrm{CH}=\mathrm{NH}(\mathbf{2})$ & $\begin{array}{l}2.7^{\mathrm{c}} \\
3.1^{\mathrm{c}}\end{array}$ & -0.2 & $\begin{array}{c}2.9 \\
3.8^{\mathrm{c}}\end{array}$ & -0.5 & $\begin{array}{l}-1.8 \\
-2.1^{\mathrm{d}}\end{array}$ & $\begin{array}{c}2.9^{\mathrm{c}} \\
3.7^{\mathrm{c}}\end{array}$ & -0.5 & $\begin{array}{l}-2.0 \\
-2.3^{\mathrm{d}}\end{array}$ \\
\hline $\begin{array}{c}\text { TS }(\mathbf{1} \text { to } 3) \\
\left(95.4^{\circ}, 96.0^{\circ}, 96.3^{\circ}\right)^{\mathrm{e}} \\
\left(96.1^{\circ}\right)\end{array}$ & $\begin{array}{l}35.5 \\
29.3^{\mathrm{c}}\end{array}$ & $-3.5^{b}$ & 35.4 & $-3.0^{b}$ & -0.6 & 35.5 & $-3.0^{b}$ & -0.9 \\
\hline $\mathrm{CH}_{2}=\mathrm{CH}-\mathrm{CH}=\mathrm{NH}(\mathbf{3})$ & $\begin{array}{c}13.4^{2} \\
11.4^{\mathrm{c}}\end{array}$ & -2.4 & $\begin{array}{c}14.3^{\mathrm{c}} \\
10.1^{\mathrm{c}}\end{array}$ & $-4.0^{\mathrm{b}, \mathrm{f}}$ & $\begin{array}{c}1.3 \\
2.6^{\mathrm{d}}\end{array}$ & $\begin{array}{l}13.0 \\
9.7^{\mathrm{c}}\end{array}$ & $-4.0^{\mathrm{b}, \mathrm{f}}$ & $\begin{array}{c}2.2 \\
3.2^{\mathrm{d}}\end{array}$ \\
\hline $\mathrm{CH}_{2}=\mathrm{CH}-\mathrm{CH}=\mathrm{NH}(4)$ & 15.1 & $-2.8^{b}$ & 16.1 & $-2.3^{b}$ & -8.7 & $\begin{array}{c}15.1^{\mathrm{c}} \\
13.1^{\mathrm{c}}\end{array}$ & $-2.5^{b}$ & $\begin{array}{l}-1.4^{2} \\
-0.9^{\mathrm{d}}\end{array}$ \\
\hline $\mathrm{O}=\mathrm{CH}-\mathrm{CH}=\mathrm{NH}(\mathbf{5})$ & 0.0 & 0.0 & 0.0 & 0.0 & 0.0 & 0.0 & 0.0 & 0.0 \\
\hline $\begin{array}{c}\mathrm{O}=\mathrm{CH}-\mathrm{CH}=\mathrm{NH}(\mathbf{6}) \\
\mathrm{TS}(\mathbf{6} \text { to } 7)\end{array}$ & 2.9 & -0.5 & 3.5 & 0.2 & -1.3 & 3.8 & 0.0 & -2.0 \\
\hline $\begin{array}{c}\left(87.3^{\circ}, 88.2^{\circ}, 88.4^{\circ}\right)^{\mathrm{e}} \\
\left(89.2^{\circ}\right)\end{array}$ & $\begin{array}{l}29.1 \\
30.8\end{array}$ & $-3.4^{b}$ & 29.9 & $-3.0^{b}$ & -3.3 & 30.4 & $-3.0^{b}$ & -4.5 \\
\hline $\mathrm{O}=\mathrm{CH}-\mathrm{CH}=\mathrm{NH}(7)$ & $\begin{array}{c}7.8^{2} \\
7.8^{\mathrm{c}}\end{array}$ & -0.1 & $\begin{array}{l}8.0 \\
9.6^{\mathrm{c}}\end{array}$ & 1.0 & $\begin{array}{c}0.4^{\mathrm{d}} \\
-1.9^{\mathrm{d}}\end{array}$ & $\begin{array}{c}8.2^{2} \\
10.5^{\mathrm{c}}\end{array}$ & 0.4 & $\begin{array}{c}0.2^{\mathrm{d}} \\
-3.0^{\mathrm{d}}\end{array}$ \\
\hline $\mathrm{O}=\mathrm{CH}-\mathrm{CH}=\mathrm{NH}(\mathbf{8})$ & $\begin{array}{l}23.1 \\
24.4\end{array}$ & $-5.4^{\mathrm{d}}$ & $\begin{array}{c}26.8 \\
32.5^{\mathrm{c}}\end{array}$ & $-3.6^{b}$ & $\begin{array}{l}-10.6 \\
-16.2^{d}\end{array}$ & $\begin{array}{c}29.0^{\mathrm{c}} \\
36.1^{\mathrm{c}}\end{array}$ & $-3.3^{b}$ & $\begin{array}{l}-14.9 \\
-22.3^{d}\end{array}$ \\
\hline $\mathrm{O}=\mathrm{C}=\mathrm{CH}-\mathrm{NH}_{2}(\mathbf{9})$ & $\begin{array}{l}20.8 \\
35.1\end{array}$ & -1.0 & $\begin{array}{c}19.7 \\
32.0^{\mathrm{c}}\end{array}$ & & $\begin{array}{c}7.4 \\
9.2^{\mathrm{d}}\end{array}$ & $\begin{array}{c}19.4 \\
31.4^{\mathrm{c}}\end{array}$ & $-0.8^{\mathrm{b}}$ & $\begin{array}{c}8.2 \\
10.3^{\mathrm{d}}\end{array}$ \\
\hline $\mathrm{HN}=\mathrm{CH}-\mathrm{CH}=\mathrm{NH}(\mathbf{1 0})$ & 0.0 & 0.0 & 0.0 & 0.0 & 0.0 & 0.0 & 0.0 & 0.0 \\
\hline $\mathrm{HN}=\mathrm{CH}-\mathrm{CH}=\mathrm{NH}$ & $\begin{array}{l}4.6 \\
6.2^{\mathrm{c}}\end{array}$ & $-2.3^{b}$ & $\begin{array}{c}5.8 \\
8.7^{\mathrm{c}}\end{array}$ & $\begin{array}{l}-2.9^{b} \\
-2.7^{b}\end{array}$ & $\begin{array}{l}-3.4 \\
-5.0^{\mathrm{d}}\end{array}$ & $\begin{array}{c}6.5 \\
9.8^{\mathrm{c}}\end{array}$ & $\begin{array}{l}-3.0^{b} \\
-2.9^{b}\end{array}$ & $\begin{array}{l}-4.8 \\
-6.8^{\mathrm{d}}\end{array}$ \\
\hline $\begin{array}{c}\text { TS }(\mathbf{1 1} \text { to } \mathbf{1 3}) \\
\left(92.7^{\circ}, 93.2^{\circ}, 93.4^{\circ}\right)^{\mathrm{e}} \\
\left(93.6^{\circ}\right)\end{array}$ & $\begin{array}{l}32.6 \\
31.3\end{array}$ & $-3.6^{b}$ & 34.3 & $-2.8^{b}$ & -5.2 & 35.2 & $-3.0^{\mathrm{b}}$ & -7.2 \\
\hline $\mathrm{HN}=\mathrm{CH}-\mathrm{CH}=\mathrm{NH}(\mathbf{1 3})$ & $\begin{array}{c}11.8 \\
10.6^{\mathrm{c}}\end{array}$ & $-2.8^{\mathrm{b}}$ & $\begin{array}{c}13.0^{\mathrm{c}} \\
13.9^{\mathrm{c}}\end{array}$ & $-3.3^{b}$ & $\begin{array}{l}-1.5 \\
-4.5^{\mathrm{d}}\end{array}$ & $\begin{array}{c}13.6 \\
15.3^{\mathrm{c}}\end{array}$ & $-4.1^{\mathrm{b}}$ & $\begin{array}{l}-2.3 \\
-6.2^{\mathrm{d}}\end{array}$ \\
\hline $\mathrm{HN}=\mathrm{CH}-\mathrm{CH}=\mathrm{NH}(\mathbf{1 2})$ & $\begin{array}{c}6.9 \\
9.4^{\mathrm{c}}\end{array}$ & -1.1 & $\begin{array}{c}7.8 \\
11.6^{\mathrm{c}}\end{array}$ & -1.4 & $\begin{array}{c}-3.6 \\
-4.9^{\mathrm{d}}\end{array}$ & $\begin{array}{c}8.2 \\
12.6^{\mathrm{c}}\end{array}$ & -1.7 & $\begin{array}{l}-4.8 \\
-7.1^{\mathrm{d}}\end{array}$ \\
\hline
\end{tabular}


Table 1. Cont.

\begin{tabular}{|c|c|c|c|c|c|c|c|c|}
\hline \multirow{2}{*}{ Structures in Schemes } & \multicolumn{2}{|c|}{ Gas } & \multicolumn{3}{|c|}{ Dichloromethane } & \multicolumn{3}{|c|}{ Water } \\
\hline & $\Delta \mathbf{E}^{\mathbf{g}_{\text {int }}}$ & $\Delta \mathbf{G}_{\text {th }}^{\mathbf{g}_{\text {}}}$ & $\Delta \mathbf{E}_{\text {int }}^{\mathbf{s}_{1}}$ & $\Delta \mathbf{G}_{\text {th }}^{\mathrm{s}}$ & $\Delta \mathbf{G}_{\text {solv }}$ & $\Delta \mathbf{E}_{\text {int }}^{s_{1}}$ & $\Delta \mathbf{G}_{\text {th }}^{\mathbf{s}}$ & $\Delta \mathbf{G}_{\text {solv }}$ \\
\hline \multirow[t]{2}{*}{$\mathrm{HN}=\mathrm{CH}-\mathrm{CH}=\mathrm{NH}(\mathbf{1 4})$} & 16.1 & & 16.7 & $-0.9^{b}$ & -3.0 & 17.0 & $-2.2^{b}$ & -4.0 \\
\hline & & & $20.8^{c}$ & & $-5.7^{\mathrm{d}}$ & $21.7^{\mathrm{c}}$ & & $-7.2^{\mathrm{d}}$ \\
\hline \multicolumn{9}{|l|}{ TS (10 to $\mathbf{1 5})$} \\
\hline$\left(86.3^{\circ},-, 93.5^{\circ}\right)^{\mathrm{e}}$ & 35.2 & $-4.0^{\mathrm{b}}$ & & & & 38.3 & $-3.8^{b}$ & -9.8 \\
\hline$\left(83.6^{\circ}\right)$ & 32.3 & & & & & & & \\
\hline \multirow[t]{2}{*}{$\mathrm{HN}=\mathrm{CH}-\mathrm{CH}=\mathrm{NH}(\mathbf{1 5})$} & 28.8 & & 33.3 & $-4.7^{b}$ & -12.8 & 36.2 & $-5.4^{b}$ & -18.5 \\
\hline & & & $36.7^{c}$ & & $-17.4^{\mathrm{c}}$ & $40.8^{c}$ & & $-24.4^{\mathrm{d}}$ \\
\hline \multirow[t]{2}{*}{$\mathrm{HN}=\mathrm{C}=\mathrm{CH}-\mathrm{NH}_{2}(\mathbf{1 6})$} & 49.2 & & 49.8 & & 0.1 & 50.2 & $-7.5^{\mathrm{g}}$ & -0.8 \\
\hline & $64.0^{\mathrm{c}}$ & & & & & & & \\
\hline $\mathrm{H}_{2} \mathrm{~N}-\mathrm{C} \equiv \mathrm{C}-\mathrm{NH}_{2}(\mathbf{1 7})$ & 98.6 & $-7.4^{\mathrm{g}}$ & 99.2 & & -2.6 & 99.2 & $-5.0^{\mathrm{g}}$ & -4.0 \\
\hline
\end{tabular}

a Values in $\mathrm{kJ} / \mathrm{mol}$. For structure numbers in parentheses, see Schemes 1 and 2. Geometries were optimized at the B97D/aug-cc-pvtz and MP2/aug-cc-pvtz levels in the indicated environment. $\Delta \mathrm{E}_{\text {int }}$ and $\Delta \mathrm{G}_{\text {solv }}$ values (upper rows) from B97D/aug-cc-pvqz single point calculations; ${ }^{\mathrm{b}}-R T \ln 2=-1.7 \mathrm{~kJ} / \mathrm{mol}$ is included in $\Delta \mathrm{G}_{\mathrm{th}}$ for the entropy of mixing for the TS antipodes or for a symmetry number of 2 for the reference structure; c $\operatorname{CCSD}(\mathrm{T})_{\mathrm{CBS}} / / \mathrm{MP} 2 /$ aug-cc-pvtz energies; ${ }^{\mathrm{d}} \mathrm{MP} 2 /$ aug-cc-pvtz value; e Values in parentheses for a TS (transition state) stand for the $\mathrm{X}=\mathrm{C}-\mathrm{C}=\mathrm{N}$ torsion angles increasing in the gas, $\mathrm{CH}_{2} \mathrm{Cl}_{2}$, and water series $\left(\mathrm{X}=\mathrm{CH}_{2}, \mathrm{O}, \mathrm{NH}\right)$. The energy/free energy parameters are provided with respect to the corresponding data of the $\mathrm{CH}_{2} \mathrm{CHCHNH}$ (1), OCHCHNH (5) and NHCHCHNH (10) conformers, respectively; ${ }^{\mathrm{f}}$ A small imaginary frequency for the lowest energy out-of-plane torsion remained through the energy minimization even using the analytical second derivative optimization. $\Delta \mathrm{G}^{\mathrm{s}}$ th was estimated by using the corresponding water frequency $\left(65 \mathrm{~cm}^{-1}\right)$, for which the normal coordinate was extremely similar. For all other water vibrations, the frequencies and the normal coordinates were very similar and deviated by $2-4 \mathrm{~cm}^{-1}$ for the low-frequency vibrations. The largest deviation has been found at $6 \mathrm{~cm}^{-1}$ above $2000 \mathrm{~cm}^{-1}$; and ${ }^{\mathrm{g}}-2 R T \ln 2=-3.4 \mathrm{~kJ} / \mathrm{mol}$ is included in the $\Delta \mathrm{G}_{\mathrm{th}}$ because of the rotational symmetry number of 2 for the reference tAA (9) form with $\mathrm{C}_{2 \mathrm{~h}}$ symmetry and due to the entropy of mixing for antipodes. TS: transition state.

Penn found, however, two s-trans conformers with $\mathrm{C}-\mathrm{C}=\mathrm{N}-\mathrm{H}$ anti (1) and syn (2) arrangements. The latter structure was predicted to be higher in energy by $3.8 \pm 0.4 \mathrm{~kJ} / \mathrm{mol}$. The calculated relative energy is 2.7 and $3.1 \mathrm{~kJ} / \mathrm{mol}$ at the DFT and the $\operatorname{CCSD}(\mathrm{T})_{\mathrm{CBS}}$ levels, respectively. But how can the anti and syn forms equilibrate in the gas phase?

The experiment was taken at $\mathrm{T}=673 \mathrm{~K}$, where a stably existing dimer is unlikely. Furthermore, as will be discussed below, a doubly hydrogen-bonded dimeric structure, preferable for a double proton-relay, is not favored even in dichloromethane solution, where a weak association trend has been still predicted. Then possible intramolecular routes for forming the $s$-trans/syn species are $\mathrm{H}$ rotation about the $\mathrm{C}=\mathrm{N}$ double bond or the nitrogen inversion.

B97D transition state geometry optimization for the s-trans/anti to s-trans/syn $\mathrm{CH}_{2} \mathrm{CHCHNH}$, starting from a $\mathrm{C}-\mathrm{C}=\mathrm{N}-\mathrm{H}$ torsion angle of $90^{\circ}$ and $\mathrm{C}=\mathrm{N}-\mathrm{H}$ bond angle of about $110^{\circ}$ as a guess for the potential energy maximum for the $\mathrm{H}$ rotation about the $\mathrm{C}=\mathrm{N}$ bond, led quickly to a $\mathrm{TS}$ geometry with $\mathrm{C}=\mathrm{N}-\mathrm{H}$ bond angle of $179.3^{\circ}$ and $\mathrm{CCNH}$ torsion angle of $124.9^{\circ}$. The torsion angle for the s-trans CCCN moiety was maintained at $180^{\circ}$. The TS structure was reoptimized at the MP level resulting in $\mathrm{CNH}$ angle of $179.2^{\circ}$ and $\mathrm{CCNH}$ and $\mathrm{CCCN}$ torsion angles of $124.5^{\circ}$ and $180.0^{\circ}$, respectively (Supplementary Table S1). These results correspond to a combined mechanism for the s-trans/anti (1) 
to s-trans/syn (2) transformation along $\mathrm{H}$ rotation about the $\mathrm{C}=\mathrm{N}$ bond and an increase in the $\mathrm{CNH}$ bond angle to almost linear, corresponding to $\mathrm{N}$-inversion. At $\mathrm{CNH}>179^{\circ}$ it is not important what the CCNH torsion angle is. B97D and MP2 predictions of the TS geometry through aug-cc-pvtz optimization are in agreement. The calculated energy barrier is, however, very high, $113.8 \mathrm{~kJ} / \mathrm{mol}$ and the activation free energy is still about $105 \mathrm{~kJ} / \mathrm{mol}$ at the B97D/aug-cc-pvqz level. The energy barrier is $123.2 \mathrm{~kJ} / \mathrm{mol}$ at the $\operatorname{CCSD}(\mathrm{T})_{\mathrm{CBS}}$ level (Table 1). The average kinetic energy for a gas molecule is $1.5 R T / \mathrm{mol}=8.4 \mathrm{~kJ} / \mathrm{mol}$ at $\mathrm{T}=673 \mathrm{~K}$, thus the necessary additional kinetic energy to distort the $s$-trans/anti structure to reach the transition state is at least $105.4 \mathrm{~kJ} / \mathrm{mol}$. From a Boltzmann distribution, the ratio of the molecules with the necessary additional energy and the average-energy molecules is about $7 \times 10^{-9}$. This is a small ratio, indeed, but even assuming only $1 \%$ for the average-energy particles, the number of the molecules with the required activation energy is $6 \times 10^{21} \times 7 \times 10^{-9} \approx 4 \times 10^{13} / \mathrm{mol}$. Thus the fraction is small but the number itself is still large, which, on the basis of the experimental results, could trigger the anti/syn equilibration.

For the $\mathrm{C}_{2} \mathrm{H}_{3} \mathrm{NO}$ molecules, the two s-trans 2-imino-acetaldehyde structures with anti and syn positions for the imino hydrogen $(5,6)$ differ by $2.9 \mathrm{~kJ} / \mathrm{mol}$ in internal energy. The B97D calculations predict the existence of both conformers in the gas phase, although the required activation energy for the equilibration is supposed to be similar to that for the corresponding $\mathrm{CH}_{2}=\mathrm{CH}-\mathrm{CH}=\mathrm{NH}$ conformers. The relative energies of the s-cis conformers (7) and mainly that of (8) are considerable at both theoretical levels predicting nearly equal values. The relative energy of (7) is, however, lower by $3.6-5.6 \mathrm{~kJ} / \mathrm{mol}$ than that for the structurally related (3) species. How can it be rationalized?

Scheme 1 shows that species (3) cannot have a strong intramolecular hydrogen bond, and could be subject only to a favorable $\mathrm{C}-\mathrm{H} \ldots \mathrm{N}$ interaction with $\mathrm{H} \ldots \mathrm{N}$ distance of $267 \mathrm{pm}$. In a recent review [30], problems related to intramolecular $v s$ intermolecular hydrogen bonds (mainly in solution for the latter) were surveyed. Upon the 2011 IUPAC (International Union of Pure and Applied Chemistry) recommendations, no clear-cut upper limit was defined for the atom separation in a X...H hydrogen bond, where $\mathrm{X}$ is generally an electronegative element. The former "golden rule" was that the $\mathrm{X}$...H bond length must be shorter than the sum of the van der Waals radii of the two atoms [31]. Then the above interaction could be qualified as a hydrogen bond since $267 \mathrm{pm}$ is within this range. An important, but not mandatory feature of a H-bond by IUPAC is the existence of a $(3,-1)$ bond criteria point (BCP). Furthermore, an important feature of a red-shifting (classical) X-H...Y hydrogen bond is that the $\mathrm{X}-\mathrm{H}$ bond length elongates with respect to the reference system without the $\mathrm{H}$-bond and charge is transferred from $\mathrm{Y}$ to the $\mathrm{X}-\mathrm{H}$. The $\mathrm{C}-\mathrm{H}$ distance from $\mathrm{B} 97 \mathrm{D}$ in (1) is $109.0 \mathrm{pm}$, the molecular electrostatic potential fitted CHELPG [32] C, H, N charges are $-0.337,0.138$, and -0.682 atomic units, respectively. The $\mathrm{C}-\mathrm{H}$ distance in (3) becomes shorter to $108.8 \mathrm{pm}$, and the corresponding atomic charges are $-0.149,0.109$, and -0.638 . Thus quite a remarkable charge was transferred from the nitrogen to the $\mathrm{C}-\mathrm{H}$ proton. The important finding was that each of the symmetrical and asymmetrical $\mathrm{C}-\mathrm{H}$ stretching frequencies increased by $10 \mathrm{~cm}^{-1}$. Taking the structural information together, the system meets all requirements for a blue-shifting hydrogen bonding, which could be, however, weak [33]. From MP2 geometry optimizations, the $\mathrm{C}-\mathrm{H}$ distance decreases from 108.3 to $108.2 \mathrm{pm}$ and the above net atomic charges are $-0.375,0.155,-0.695$ vs. $-0.189,0.123$, and -0.647 . The differences in the sets by the two methods are close. 
For the pair of (6) and (7), the B97D/aug-cc-pvtz calculated $\mathrm{N}-\mathrm{H}$ bond length increases from 102.5 in (6) to $103.1 \mathrm{in} \mathrm{(7),} \mathrm{the} \mathrm{stretching} \mathrm{frequency} \mathrm{decreases} \mathrm{from} 3370$ to $3296 \mathrm{~cm}^{-1}$, and the calculated atomic charges for $\mathrm{O}, \mathrm{H}, \mathrm{N}$ are $-0.444,0.358$, and -0656 , respectively, in (6) compared with $-0.408,0.317$, and -0.562 in (7). The $\mathrm{O} \ldots \mathrm{H}$ separation is $245.0 \mathrm{pm}$ in (7), the $\mathrm{O} \ldots \mathrm{H}-\mathrm{N}$ bond angle is $105.4^{\circ}$. It is questionable whether such a bent bond still can be assigned to a hydrogen bond category, but the effect of the interactions to the important structural parameters for a red-shifting hydrogen bond formation has been clearly demonstrated. Even if the interaction is only pure electrostatic, the decrease of the relative energy from $11.4-13.4 \mathrm{~kJ} / \mathrm{mol}$ for (3) to 7.8 for (7) is reasonable.

The transition state activation energy from (6) to (7) was calculated at $29.1-30.8 \mathrm{~kJ} / \mathrm{mol}$ with OCCN torsion angles of $87.3^{\circ}-89.2^{\circ}$. The barrier can be overridden upon collision in the gas-phase, and species (7) can be present with (5):(7) ratio of about 4:96 at room temperature. The large relative energy for (8) can be attributed to the repulsion of the nitrogen and oxygen lone pairs existing in the almost planar heavy atom arrangement with OCCN torsion angle of $0.4^{\circ}$ (Table S1).

The amino ketene tautomer (9) is higher in energy then species (5) by $20.8 \mathrm{~kJ} / \mathrm{mol}$ and $35.1 \mathrm{~kJ} / \mathrm{mol}$ at the DFT and the $a b$ initio level, respectively. The calculated values suggest that the predominant conformer/tautomer in the gas phase is structure (5). If the large, possibly about $100 \mathrm{~kJ} / \mathrm{mol}$, activation energy can be provided in the gas phase for the formation of (6) (in analogy to the formation of (2), as was proven by the experiment of Penn [29], the calculated (5):(6) equilibrium ratio is 28:72 (the final equilibrium composition depends on all considered species existing in the mixture but the ratios for selected pairs will not change).

For the studied $\mathrm{C}_{2} \mathrm{H}_{4} \mathrm{~N}_{2}$ systems (the isomeric $\mathrm{H}_{2} \mathrm{~N}-\mathrm{CH}_{2}-\mathrm{CN}$ amino-acetonitrile was not investigated), the prevalent 1,2-ethanediimine species is the (10, tAA) (see Scheme 2) in the gas phase. It is more stable in free energy by $2.3-5.8 \mathrm{~kJ} / \mathrm{mol}$ than $(11, \mathrm{tAS})$ and $(12, \mathrm{tSS})$ at the DFT level and must be more stable by a further $2-3 \mathrm{~kJ} / \mathrm{mol}$ than species (11) and (12) as calculated ab initio. The relative energies of the $s$-cis conformers (13-15) were calculated at 11-29 kJ/mol. Relative energies are even much higher for the amino imino-ketene (16) with a cumulated double-bonded structure and the 1,2-diamino acetylene (17). The values calculated at the DFT level are 49 and $99 \mathrm{~kJ} / \mathrm{mol}$, respectively. The $\operatorname{CCSD}(\mathrm{T})_{\mathrm{CBS}}$ relative energy for structure (16) is $64 \mathrm{~kJ} / \mathrm{mol}$. The analysis of the energy components in Equation (2) (section 3) revealed that the $\Delta \mathrm{E}^{\mathrm{MP2}} \mathrm{CBS}$ term is about $90 \%$ responsible for the indicated relative energy, whereas $\left(\Delta \mathrm{E}^{\mathrm{CCSD}(\mathrm{T})}-\Delta \mathrm{E}^{\mathrm{MP} 2}\right)$ aug-cc-pvdz accounts for the about $10 \%$ remaining. This means that the post-MP2 correction is meaningful for tautomeric systems $(5.33 \mathrm{~kJ} / \mathrm{mol}$ in the present case). The relative post-MP2 correction accounted for an even larger share of the total relative internal energy for species (9). Its contribution to the final value of $35.1 \mathrm{~kJ} / \mathrm{mol} \mathrm{was} 10.1 \mathrm{~kJ} / \mathrm{mol}$. In contrast, the $\left(\Delta \mathrm{E}^{\mathrm{CCSD}(\mathrm{T})}-\Delta \mathrm{E}^{\mathrm{MP2}}\right)$ aug-cc-pvdz contributions to the relative conformational internal energies have been found to be small, amounting only to $1-2 \mathrm{~kJ} / \mathrm{mol}$ in general.

The (11) to (13) conformational change is possible along a rotation about the NCCN bond. The transition state torsion angle was predicted at $92.7^{\circ}-93.6^{\circ}$ by the two theoretical approaches with activation energy of 31-33 kJ/mol. The activation free energy must be smaller by $11 \%$ from B97D estimation. When (13) is formed the question can be raised whether there is an $\mathrm{N}-\mathrm{H}$... $\mathrm{N}$ hydrogen bond. Present computational results cannot give a unique answer. The right-hand side $\mathrm{N}-\mathrm{H}$ bond length of $102.94 \mathrm{pm}$ in $13 \mathrm{cAS}$ (Scheme 2) shows a very little increase from $102.88 \mathrm{pm}$ in $11 \mathrm{tAS}$. 
Scheme 2 clarifies that this $\mathrm{N}-\mathrm{H}$ bond ( $\mathrm{CCNH}$ syn) can act as the hydrogen bond donor, whereas the left-hand side nitrogen (CCNH anti) would be the acceptor atom. The small increase of the syn $\mathrm{N}-\mathrm{H}$ bond in combination with a remarkable charge transfer from the nitrogen in the CCNH anti moiety, (atomic charges on this nitrogen are -0.670 and -0.637 in (11) and (13) respectively) suggest a red-shifting hydrogen bond. However, the vibrational frequency for the syn $\mathrm{N}-\mathrm{H}$ bond increases from $3306 \mathrm{~cm}^{-1}$ in (11) to $3312 \mathrm{~cm}^{-1}$ in (13). Since the bond length increases (even though very slightly), a small decrease instead of the noted small increase in the vibrational frequency would have been expected. For the other $\mathrm{N}-\mathrm{H}$ bond in the $\mathrm{CCNH}$ anti substructure, the bond length decreased from $102.37 \mathrm{pm}$ in (11) to $102.21 \mathrm{pm}$ in (13) and the concomitant frequency change was an increase from 3377 to $3398 \mathrm{~cm}^{-1}$. The N...H distance was calculated at $245.9 \mathrm{pm}$ at the B97D level with $\mathrm{N}-\mathrm{H}$... N bond angle of $105.6^{\circ}$. These geometric data would still comply with a strongly bent regular H-bond, although it was unable to identify the hydrogen bond character in the gas phase on the basis of the above contradictory data. In contrast, the stretching frequency of the donor $\mathrm{N}-\mathrm{H}$ in the $s$-cis/syn conformation decreased by 10 and $20 \mathrm{~cm}^{-1}$ in dichloromethane and water, respectively, completing the required conditions for a red-shifting intramolecular hydrogen bond.

Finally, the transformation of species (10) to (15) was studied through rotation about the $\mathrm{C}-\mathrm{C}$ bond. The NCCN torsion angle is $83.6^{\circ}-86.3^{\circ}$ in the transition state with energy $32-35 \mathrm{~kJ} / \mathrm{mol}$ above that for the reference (10) conformation. The two theoretical methods thus provide similar results. Conformer (15) corresponds to a NCCN s-cis structure with two HNCC anti moieties (cAA in Scheme 2). Although the molecule is not planar, the NCCN torsion angle of $26.8^{\circ}$ could only partially diminish the repulsion of the nitrogen lone pairs. Consequently, the relative energy is high, $28.8 \mathrm{~kJ} / \mathrm{mol}$ at the B97D level and the conformer is not expected to appear in the gas-phase equilibrium mixture.

Whereas no comparison of the calculated relative energies for the studied $\mathrm{C}_{2} \mathrm{H}_{4} \mathrm{~N}_{2}$ systems is possible in the absence of experimental data for 1,2-ethanediimine itself, Hargittai and Seip [34] investigated the molecular structure of its $N, N^{\prime}$-di-tertiary butyl derivative by gas electron diffraction. The predominant structure was found gauche with $\mathrm{N}=\mathrm{C}-\mathrm{C}=\mathrm{N}$ torsion angle of $65^{\circ}$ by a rotation from the syn form (corresponding to $s$-cis in this paper), although a small fraction of the anti (s-trans) conformer was also assigned. The present author attributes this experimental result mainly to the favorable dispersion interactions of the two bulky t-butyl groups in the gauche rather than in the $s$-trans form, and the decrease of the relative free energy by $R T \ln 2=2.03 \mathrm{~kJ} / \mathrm{mol}$ at the temperature of the experiment $(\sim 353 \mathrm{~K})$ due to the mixing of the two optical antipodes emerging in the case of a gauche structure.

A structure, closely related to 1,2-diamino acetylene, $\mu_{2}, \eta^{2}-1,2$-diaminoethylene was characterized by using Fourier transform-reflection absorption infrared spectroscopy (FT-RAIRS) as a surface species [35]. The $\mathrm{C}$ atoms in this structure are bound to a $\mathrm{Pt}$ surface and the spectra predicted a $\mathrm{H}_{2} \mathrm{~N}-\mathrm{C}-\mathrm{C}-\mathrm{NH}_{2}$ moiety, with delocalized $\pi$ electrons along the NCCN path. Two different amino $\mathrm{N}-\mathrm{H}$ stretching frequencies were assigned according to the $\mathrm{C}_{2 \mathrm{v}}$ symmetry. The relevance of this result with respect to the present study is that no imine frequencies were assigned. Thus the $\mathrm{H}_{2} \mathrm{~N}-\mathrm{C} \equiv \mathrm{C}-\mathrm{NH}_{2}$ tautomer could be also stable in the gas phase in spite of its about $99 \mathrm{~kJ} / \mathrm{mol}$ relative energy. 


\subsection{In-Solution Results}

Table 1 summarizes the results of the quantum mechanical calculations for solutes in dichloromethane and water solvents, as well. Internal energy differences and IEF-PCM $/ \Delta \mathrm{G}_{\text {solv }}$ values were obtained from B97D/aug-cc-pvqz/B97D/aug-cc-pvtz single point calculations in every case. In a number of cases, relative internal energies were calculated from $\operatorname{CCSD}(\mathrm{T})_{\mathrm{CBS}}$ values following the IEF-PCM/MP2/aug-cc-pvtz geometry optimization. The related $\Delta \mathrm{G}_{\text {solv }}$ values were obtained at this optimization level.

The energy of a structure, $\mathrm{E}^{\mathrm{g}}$ int, is lowest at a theoretical level if the geometry is optimized in the gas phase. If the molecule is imbedded in a solvent environment, its internal energy will increase: $E_{\text {int }}^{s_{i}}$ becomes less negative than $\mathrm{E}_{\text {int }}$ in order to make $\mathrm{G}_{\text {solv }} / \mathrm{PCM}$ optimally negative. The SCF (self-consistent field) procedure through the IEF-PCM in-solution geometry optimization stops where the ( $\left.\mathrm{E}_{\text {int }}+\mathrm{G}_{\text {solv }}\right)$ term reaches a local minimum. Increase of the internal energy has two sources: the geometry distortion as compared to the gas-phase structure and the solute polarization. Table S1 shows that the main geometric parameters change only slightly due to solvation, thus the increase of Eint in solution must be attributed mainly to polarization effects. In a former study, Alagona et al. [36] calculated the separate effects of the two contributions for small molecules, and the polarization effect was found to be of significantly larger importance in DFT calculations.

$\Delta \mathrm{E}^{\mathrm{S}}$ in from IEF-PCM/B97D calculations are both larger and smaller than the corresponding gas-phase values by $1-2 \mathrm{~kJ} / \mathrm{mol}$ in general. It is worth mentioning that this feature of the relative internal energy is allowed theoretically upon solvation, whereas the individual Eint values always increase. The variation of the in-solution $\Delta \mathrm{E}^{\mathrm{s}}$ int value in comparison with its gas-phase counterpart, $\Delta \mathrm{E}^{\mathrm{g}}{ }_{\text {int, }}$, depends on which species undergoes smaller energy increase upon solvation. The smaller increase in $\mathrm{E}_{\text {int }}$ for the more stable form leads to an increased $\Delta \mathrm{E}^{\mathrm{s}}$ int and vice versa.

Remarkable increases in $\Delta \mathrm{E}_{\text {int }}$ were obtained for structures (8) and (15) with outstandingly large solvent effects in water. Since $\Delta \mathrm{G}_{\text {solv }} / \mathrm{PCM}$ is conspicuously negative, the concomitant $\Delta \mathrm{E}^{\mathrm{s}}$ int values increased by 5.9 and $7.4 \mathrm{~kJ} / \mathrm{mol}$ as compared with $\Delta \mathrm{E}^{\mathrm{g}_{\mathrm{int}}}$ of 23.1 and $28.8 \mathrm{~kJ} / \mathrm{mol}$, respectively, suggesting considerable internal energy increases for structures (8) and (15) in aqueous solution.

Bond lengths and bond angles change negligibly upon solvation. In contrast, the XCCY torsion angles for heavy atoms significantly deviate from $0^{\circ}$ or $180^{\circ}$ in solution for species (4), (8), and (15). The heavy atoms in tautomers (9) and (16) are far from coplanarity even in the gas phase. The solvation changes the XCCY torsion angles only slightly. Indicated HNNH torsion angles for (17) in Supplementary Table S1 also do not change remarkably leaving the structure without any symmetry.

The in-solution $\Delta \mathrm{G}^{\mathrm{s}}$ th values are generally moderate in comparison with the corresponding $\Delta \mathrm{E}^{\mathrm{s}}$ int values. The gas-phase molecular symmetries were preserved in solution, thus the related entropy contributions to the corresponding $\mathrm{G}_{\text {th }}^{\mathrm{s}}$ values still hold. The sign of the $\Delta \mathrm{E}_{\text {int }}^{\mathrm{s}}+\Delta \mathrm{G}^{\mathrm{s}}$ th $+\Delta \mathrm{G}_{\text {solv }} / \mathrm{PCM}$ sum was always dominated by the sign of the $\Delta \mathrm{E}^{\mathrm{s}_{\text {int }}}$ term. Accordingly, the sign of the total relative free energy, $\Delta \mathrm{G}^{\mathrm{s}}$ tot is equal to that for $\Delta \mathrm{E}^{\mathrm{s}}$ int in every case.

IEF-PCM/CCSD $(\mathrm{T})_{\mathrm{CBS}}$ calculations predicted that $\Delta \mathrm{E}_{\text {int }}^{\mathrm{s}_{\mathrm{n}}}$ would increase for the conformers by up to $7.1 \mathrm{~kJ} / \mathrm{mol}$ (except (3) and (4) with a decrease up to $4.2 \mathrm{~kJ} / \mathrm{mol}$ ) as compared with the B97D/aug-cc-pvqz result for structures in dichloromethane and water, and the increase by about $12.0 \mathrm{~kJ} / \mathrm{mol}$ for species (9) is similar to that found for this latter tautomer in the gas-phase. The most 
surprising result was, however, that the IEF-PCM/MP2/aug-cc-pvtz $\Delta \mathrm{G}_{\text {solv }}$ for (7) was significantly negative in comparison with the small positive value by the DFT calculations. In other cases, the MP2/aug-cc-pvtz relative solvation free energies preserved at least the sign of $\Delta \mathrm{G}_{\mathrm{solv}} / \mathrm{PCM}$ as calculated by $\mathrm{B} 97 \mathrm{D}$. In general, if the ab initio $\Delta \mathrm{E}^{\mathrm{s}}$ int increases, the related $\mathrm{MP} 2 / \Delta \mathrm{G}_{\text {solv }}$ becomes more negative for the conformers and vice versa. The deviations call attention to the probably different account for the solute polarization by the two theoretical methods. For tautomer (9), however, both $\Delta \mathrm{E}_{\text {int }}^{\mathrm{s}}$ and $\Delta \mathrm{G}_{\text {solv }} / \mathrm{PCM}$ increase.

IEF-PCM relative solvation free energies for conformational local energy minima scatter in a wide range of 3.2 and $-24.4 \mathrm{~kJ} / \mathrm{mol}$, whereas those for tautomers $(9,16,17)$ vary between 10.3 and $-4.0 \mathrm{~kJ} / \mathrm{mol}$. The remarkable cases from the point of view of the estimation of the equilibrium composition are when the $\Delta \mathrm{E}^{\mathrm{s}}$ int and $\Delta \mathrm{G}_{\text {solv }}$ values are of opposite signs, thus when $\Delta \mathrm{G}_{\text {solv }}$ is negative in Table 1 (with positive $\Delta \mathrm{G}_{\text {solv }} / \mathrm{PCM}$, the species is even less preferable than calculated on the basis of the $\Delta \mathrm{E}_{\text {int }}^{\mathrm{s}_{\mathrm{i}}}+\Delta \mathrm{G}_{\text {th }}^{\mathrm{s}}$ term). For $\mathrm{CH}_{2}=\mathrm{CH}-\mathrm{CH}=\mathrm{NH}(2), \Delta \mathrm{G}_{\text {tot }}^{\mathrm{s}}$ from B97D is only $0.4-0.6 \mathrm{~kJ} / \mathrm{mol}$, considerably smaller than the gas-phase value of $2.5 \mathrm{~kJ} / \mathrm{mol}$. The reduction means that the (2), the $s$-trans/syn fraction is $44 \%-46 \%$ of the total s-trans form in solution at room temperature. For $\mathrm{O}=\mathrm{CH}-\mathrm{CH}=\mathrm{NH}(6)$, also at $\mathrm{T}=298 \mathrm{~K}$, the $\mathrm{B} 97 \mathrm{D} \Delta \mathrm{G}_{\text {tot }}^{\mathrm{s}}$ values are 2.4 and $1.8 \mathrm{~kJ} / \mathrm{mol}$ in dichloromethane and water, respectively, corresponding to 28:72 and 33:67 molar fractions in the respective solvents for the less and more stable s-trans conformers with the $\mathrm{H}-\mathrm{N}$ bond pointing in different directions. The ratio is about 24:76 in the gas phase as calculated from energies, thus the solvent effects are small for the s-trans 2-imino-acetaldehyde.

The most stable conformation of 1,2-ethanediimine seems to be a delicate question at the IEF-PCM level. Whereas (10), the s-trans/anti/anti conformation is clearly the most stable in the gas phase, $\Delta \mathrm{G}_{\text {tot }}^{\mathrm{s}}$ for the (11) s-trans/anti/syn conformation is -0.5 and $-1.3 \mathrm{~kJ} / \mathrm{mol}$ in dichloromethane and water, respectively, at the B97D level. For a comparable estimation, the time-consuming MP2/aug-cc-pvtz frequencies were calculated for the corresponding pair, showing that the derived $\Delta \mathrm{G}^{\mathrm{s}}$ th values hardly deviated from the B97D values in the four cases studied. This finding supports that one may use the B97D values in other cases, as well, when the relative $\operatorname{CCSD}(\mathrm{T})_{\mathrm{CBS}}$ free energies are to be calculated. For the present case, (10) is just slightly more stable than (11) at the ab initio level even in aqueous solution. Nonetheless, the problem will be studied using the FEP/MC method and discussed below.

In the s-cis/anti/anti conformation of $\mathrm{HN}=\mathrm{CH}-\mathrm{CH}=\mathrm{NH}$ (15), when the two lone pairs of the nitrogen atoms point mostly toward each other, the relative internal energy largely increases compared with (13) and (14). Although the considerably more negative $\Delta \Delta \mathrm{G}_{\text {solv }} / \mathrm{PCM}$ values in water indicates that the solvation strongly supports the formation of this conformer, $\Delta \mathrm{G}^{\mathrm{s}}$ tot remains too positive preventing the observable appearance of this conformer in the equilibrium mixture.

$\Delta \mathrm{G}_{\text {solv }} / \mathrm{PCM}$ values are negative for the TS structures regarding rotations about the central $\mathrm{C}-\mathrm{C}$ bond. All calculated XCCN torsion angles for such conformer transformations are about $90^{\circ}$. Apparently, solvation favors the nearly perpendicular rather than coplanar arrangements for the XCC and CCY planes of the heavy atoms. In contrast, $\Delta \mathrm{G}_{\text {solv }} / \mathrm{PCM}$ for the TS corresponding to the combined $\mathrm{H}$ rotation about the $\mathrm{C}=\mathrm{N}$ bond/ $\mathrm{N}$-inversion for the $s$-trans $\mathrm{CH}_{2}=\mathrm{CH}-\mathrm{CH}=\mathrm{NH}$ is strongly positive, with coplanar CCCN skeleton. 
A well-known shortcoming of the continuum dielectric solvent model is that it may underestimate the solvation effects on the possible solute-solvent hydrogen bonds, when the pure solute is placed into the cavity carved within the solvent. For improving the performance of the IEF-PCM, a supermolecule may be considered, where the solute is surrounded by a number of water molecules and this supermolecule is embedded into the cavity within the continuum solvent. To this aim, tetrahydrate models have been studied for two solutes in two conformations for each (Figure 1). By an explicit solvent Monte Carlo method, the thermally averaged solute-solvent hydrogen bond interactions can be considered. In the present, classical MC, the solute has to be characterized by preset net atomic charges, which can be derived by a fit to the in-solution molecular electrostatic potential (Table 2).

In the optimized tetrahydrate structures, the OCCN and NCCN torsion angles are about $180^{\circ}$ for $5 \mathrm{tA}$ and $10 \mathrm{tAA}$ in accord with their values for the pure solute in the water cavity, whereas the torsion angles for $8 \mathrm{cA}$ and $15 \mathrm{cAA}$ increase by $12^{\circ}-17^{\circ}$ as compared with their B97D values in Table S1. There are four solute-solvent hydrogen bonds to $5 \mathrm{tA}, 10 \mathrm{tAA}$, and $15 \mathrm{cAA}$. In $8 \mathrm{cA}$ a water-water hydrogen bond (w1...w2) comes into existence instead of a $=\mathrm{O} \ldots \mathrm{H}_{\mathrm{w} 21} \mathrm{O}_{\mathrm{w} 2}$ bond. The hydrogen bonds are shorter when the water hydrogen is the donor than when a $\mathrm{N}-\mathrm{H} . . \mathrm{O}_{\mathrm{w}}$ bond is formed.

The problems related to the supermolecule approach when considering a limited number of water molecules becomes evident by the structures in Figure 1. The four hydrogen-bonding sites are far from each other in $5 \mathrm{tA}$ and $10 \mathrm{tAA}$ and the connecting water molecules cannot form a water-water hydrogen bond in parallel with the formation of solute-water hydrogen bonds. In the $s$-cis conformations, a three-member water chain is formed for $8 \mathrm{cA}$ and a water-water hydrogen bond is stable in 15 tAA. As a result, the $s$-cis imino-aldehyde tetrahydrate $(8 \mathrm{cA})$ is more stable than the $s$-trans $(5 \mathrm{tA})$ tetrahydrate by $2.7 \mathrm{~kJ} / \mathrm{mol}$, in comparison with the relative $\Delta \mathrm{E}^{\mathrm{s}}$ int $+\Delta \mathrm{G}_{\text {solv }} / \mathrm{PCM}$ energies of $29.1-14.9=14.2 \mathrm{~kJ} / \mathrm{mol}$ for the pure $8 \mathrm{cA}$ solute at the IEF-PCM/B97D/aug-cc-pvtz level (Table 1 contains aug-cc-pvqz values). The tetrahydrate result is a consequence of the two water-water hydrogen bonds along the three-water chain. Their BSSE-corrected interaction energy in the gas phase (no BSSE available in IEF-PCM) is $25.4 \mathrm{~kJ} / \mathrm{mol}$. If the relative tetrahydrate energy is corrected by this value, the s-cis $8 \mathrm{cA}$ system becomes $22.7 \mathrm{~kJ} / \mathrm{mol}$ less stable than the $5 \mathrm{tA}$ tetrahydrate vs $14.2 \mathrm{~kJ} / \mathrm{mol}$ for the pure solutes. This correction is justified, because the water bridges, affecting the total energy only for $8 \mathrm{cA}$, specifically emerge for this structure due to considering only a limited number for explicit water molecules.

In a real system, each water molecule in the first hydration shell is in hydrogen bond(s) with waters in the second shell or with those around the $\mathrm{CH}$ sites, thus the discussed peculiarity will not be relevant. In an aqueous solution, w1, w2, and w3 of 5 tA are also in hydrogen bonds with its neighbors, and w4 for both conformers, too. In conclusion, the reversal of the relative energy is the consequence of considering only four water molecules in the supermolecule. 


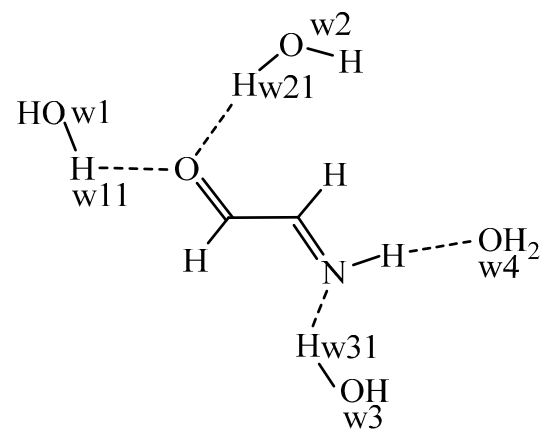

5 tA

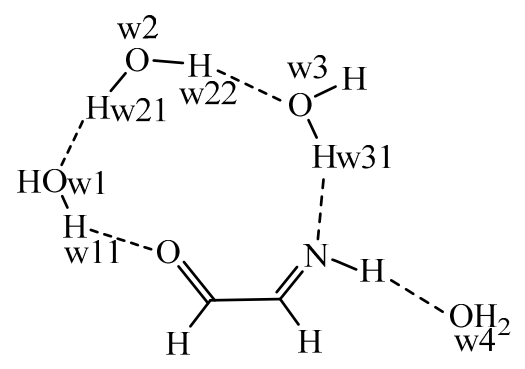

$8 \mathrm{cA}$

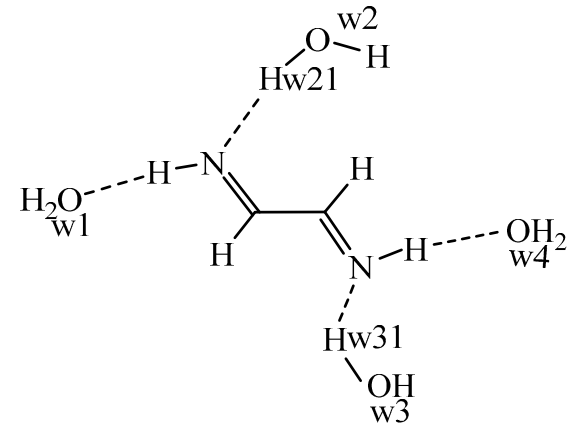

10 tAA

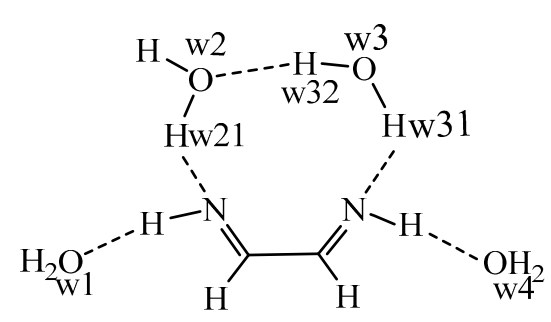

$15 \mathrm{cAA}$

Figure 1. The structures of the tetrahydrates of the s-trans species 5 and 10 and the $s$-cis species 8 and 15 as optimized in continuum water solvent at the IEF-PCM/B97D/ aug-cc-pvtz level. The hydrogen bond parameters (from left to right) in Figure 1 are as follow. $5 \mathrm{tA}$ : $\mathrm{OCCN}=180^{\circ}$, the $\mathrm{O}=\mathrm{C}, \mathrm{O} \ldots \mathrm{H}_{\mathrm{w} 11}(198 \mathrm{pm})$, and $\mathrm{O} \ldots \mathrm{H}_{\mathrm{w} 21}(201 \mathrm{pm})$ bonds are coplanar, bond angles: $\mathrm{O}_{\mathrm{w} 1} \mathrm{H}_{\mathrm{w} 11} \ldots \mathrm{O}=177^{\circ}, \mathrm{O}_{\mathrm{w} 2} \mathrm{H}_{\mathrm{w} 21} \ldots \mathrm{O}=178^{\circ}$. The $\mathrm{C}=\mathrm{N}, \mathrm{N}-\mathrm{H}$ and the $\mathrm{N} . . . \mathrm{H}_{\mathrm{w} 31}(187 \mathrm{pm})$ bonds are coplanar, $\mathrm{H} . . . \mathrm{O}_{\mathrm{w} 4}=208 \mathrm{pm}$. The $\mathrm{N} . . \mathrm{H}_{\mathrm{w} 31} \mathrm{O}_{\mathrm{w} 3}$ bond angle is $177^{\circ}, \mathrm{N}-\mathrm{H} . . . \mathrm{O}_{\mathrm{w} 4}=173^{\circ} .10$ tAA: $\mathrm{NCCN}=179.9^{\circ}$, the $\mathrm{N}=\mathrm{C}, \mathrm{N}-\mathrm{H}$, and $\mathrm{N} . . \mathrm{H}_{\mathrm{w} 21}$

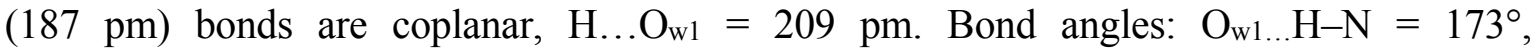
$\mathrm{O}_{\mathrm{w} 2} \mathrm{H}_{\mathrm{w} 21 \ldots \mathrm{N}}=177^{\circ}$. The $\mathrm{C}=\mathrm{N}, \mathrm{N}-\mathrm{H}$ and the $\mathrm{N} \ldots \mathrm{H}_{\mathrm{w} 31}(187 \mathrm{pm})$ bonds are coplanar, $\mathrm{H} . . . \mathrm{O}_{\mathrm{w} 4}=208 \mathrm{pm}$. The $\mathrm{N}_{\ldots} . . \mathrm{H}_{\mathrm{w} 31} \mathrm{O}_{\mathrm{w} 3}$ bond angle is $177^{\circ}, \mathrm{N}-\mathrm{H} \ldots \mathrm{O}_{\mathrm{w} 4}=173^{\circ} .8 \mathrm{cA}$ : OCCN $=23.7^{\circ}$, only one water-carbonyl hydrogen bond: O...H $\mathrm{H}_{\mathrm{w} 11}(194 \mathrm{pm})$, $\mathrm{O}_{\mathrm{w} 1} \mathrm{H}_{\mathrm{w} 11 \ldots \mathrm{O}}=161^{\circ}$. Waters 1 and 2 form a solvent-solvent hydrogen bond with $\mathrm{O}_{\mathrm{w} 1} \ldots \mathrm{H}_{\mathrm{w} 21}$ distance of $194 \mathrm{pm}$ and $\mathrm{O}_{\mathrm{w} 1} \ldots \mathrm{H}_{\mathrm{w} 21} \mathrm{O}_{\mathrm{w} 2}$ angle of $177^{\circ}$. Water 2 and water 3

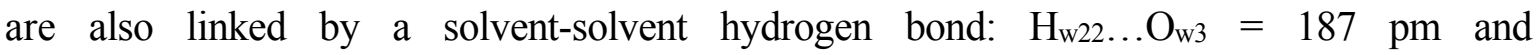

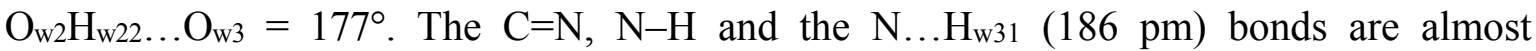
coplanar (the sum of the bond angles is $359^{\circ}$ ), $\mathrm{H} \ldots \mathrm{O}_{\mathrm{w} 4}=201 \mathrm{pm}$. The $\mathrm{N} \ldots \mathrm{H}_{\mathrm{w} 31} \mathrm{O}_{\mathrm{w} 3}$ bond angle is $178^{\circ}, \mathrm{N}-\mathrm{H} \ldots \mathrm{O}_{\mathrm{w} 4}=176^{\circ} .15 \mathrm{cAA}$ : $\mathrm{NCCN}=30.5^{\circ}$, the $\mathrm{N}=\mathrm{C}, \mathrm{N}-\mathrm{H}$, and $\mathrm{N} \ldots \mathrm{H}_{\mathrm{w} 21}$

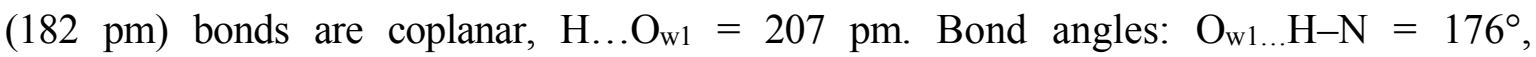
$\mathrm{O}_{\mathrm{w} 2} \mathrm{H}_{\mathrm{w} 21} \ldots \mathrm{N}=177^{\circ}$. Water 2 and water 3 form a solvent-solvent hydrogen bond: $\mathrm{O}_{\mathrm{w} 2} \ldots \mathrm{H}_{\mathrm{w} 32}=193 \mathrm{pm}$ and $\mathrm{O}_{\mathrm{w} 2} \ldots \mathrm{H}_{\mathrm{w} 32} \mathrm{O}_{\mathrm{w} 3}=161^{\circ}$. The $\mathrm{C}=\mathrm{N}, \mathrm{N}-\mathrm{H}$ and the $\mathrm{N} \ldots \mathrm{H}_{\mathrm{w} 31}$ $(190 \mathrm{pm})$ bonds are coplanar, $\mathrm{H} . . . \mathrm{O}_{\mathrm{w} 4}=210 \mathrm{pm}$. The $\mathrm{N} . . . \mathrm{H}_{\mathrm{w} 31} \mathrm{O}_{\mathrm{w} 3}$ bond angle is $175^{\circ}$, $\mathrm{N}-\mathrm{H} . . . \mathrm{O}_{\mathrm{w} 4}=172^{\circ}$. 
Table 2. B97D/aug-cc-pvtz polar atomic and net solute charges from IEF-PCM calculations ${ }^{\mathrm{a}}$.

\begin{tabular}{|c|c|c|c|c|c|}
\hline \multirow{2}{*}{ Structures in Schemes } & \multirow{2}{*}{$\begin{array}{l}\text { Polar } \\
\text { Atoms }\end{array}$} & \multirow{2}{*}{ Pure Solute } & \multirow{2}{*}{ Solute $+4 \mathrm{H}_{2} \mathrm{O}$} & \multicolumn{2}{|c|}{ Net Solute Charges } \\
\hline & & & & Pure Solute & in Supermolecule \\
\hline \multirow[t]{3}{*}{$\mathrm{O}=\mathrm{CH}-\mathrm{CH}=\mathrm{NH}(\mathbf{5})$} & $\mathrm{O}$ & -0.510 & -0.340 & 0.000 & 0.268 \\
\hline & $\mathrm{N}$ & -0.754 & -0.495 & & \\
\hline & $\mathrm{H}$ & 0.419 & 0.406 & & \\
\hline \multirow[t]{3}{*}{$\mathrm{O}=\mathrm{CH}-\mathrm{CH}=\mathrm{NH}(\mathbf{8})$} & $\mathrm{O}$ & -0.488 & -0.389 & 0.000 & 0.184 \\
\hline & $\mathrm{N}$ & -0.726 & -0.489 & & \\
\hline & $\mathrm{H}$ & 0.404 & 0.368 & & \\
\hline \multirow[t]{4}{*}{$\mathrm{HN}=\mathrm{CH}-\mathrm{CH}=\mathrm{NH}(\mathbf{1 0})$} & $\mathrm{H}$ & 0.404 & 0.460 & 0.000 & 0.186 \\
\hline & $\mathrm{N}$ & -0.800 & -0.666 & & \\
\hline & $\mathrm{N}$ & -0.800 & -0.641 & & \\
\hline & $\mathrm{H}$ & 0.404 & 0.439 & & \\
\hline \multirow[t]{4}{*}{$\mathrm{HN}=\mathrm{CH}-\mathrm{CH}=\mathrm{NH}(\mathbf{1 5})$} & $\mathrm{H}$ & 0.388 & 0.354 & 0.000 & 0.208 \\
\hline & $\mathrm{N}$ & -0.757 & -0.531 & & \\
\hline & $\mathrm{N}$ & -0.757 & -0.479 & & \\
\hline & $\mathrm{H}$ & 0.388 & 0.325 & & \\
\hline
\end{tabular}

a For structure numbers in parentheses, see Schemes 1 and 2. Geometries were optimized at the IEF-PCM/B97D/aug-cc-pvtz level in aqueous solution. Charges were derived by their CHELPG fit the in-solution molecular electrostatic potentials.

The same analysis can be performed for the 1,2-ethanediimine conformers. In this case, 10 tAA is still more stable than $15 \mathrm{cAA}$ by $9.8 \mathrm{~kJ} / \mathrm{mol}$ in comparison with $\Delta \mathrm{E}_{\text {int }}^{\mathrm{s}}+\Delta \mathrm{G}_{\text {solv }} / \mathrm{PCM}$ of $36.3-18.6=17.7 \mathrm{~kJ} / \mathrm{mol}$ for the pure solutes. The correct preference was still maintained because there is only one water-water hydrogen bond in $15 \mathrm{cAA}$, for which the BSSE corrected interaction energy is $-11.0 \mathrm{~kJ} / \mathrm{mol}$. Considering this term, 10 tAA becomes more stable than $15 \mathrm{cAA}$ by $20.8 \mathrm{~kJ} / \mathrm{mol}$, near the relative in-solution energy for the pure solutes. In the transition state, no water-water hydrogen bond formation was noticed. The NCCN torsion angle was found as $95.1^{\circ}$ in comparison with $93.5^{\circ}$ for the pure solute. The tetrahydrate transition state is higher in energy by $27 \mathrm{~kJ} / \mathrm{mol}$ compared with the calculated value of $38.3-9.8=28.5 \mathrm{~kJ} / \mathrm{mol}$ for the pure solute. The agreement is very good; consideration of explicit water molecules for the transition state along the s-trans to s-cis transformation results in only a small energy decrease.

As a partial summary, supermolecule models in a continuum dielectric solvent may distort the relative energies if only a limited number of water molecules are considered. In some solute conformations the water molecules may form water-water hydrogen bonds, whereas such bonds do not appear in the case of other solute structures. The water-water hydrogen bond interactions make the related supermolecule energy artificially too negative. This phenomenon typically emerges for conformational equilibrium calculations of small molecules with two, near polar sites open to form solute-water hydrogen bonds. If the relative energies are approximately corrected by the water-water hydrogen-bond interactions existing in one but not in another conformation, the calculated relative energies differ by less than $8 \mathrm{~kJ} / \mathrm{mol}$ in comparison with the pure solute in-solution energies in the cases studied here at the B97D/aug-cc-pvtz level. 
Nonetheless, the optimized tetrahydrate structures can well be compared with the derived first hydration shell structure of different conformers to be discussed below. Those results stem from Monte Carlo simulations, for which IEF-PCM derived net atomic charges have been utilized (Table 2).

In a hydrogen bond, charges are always transferred from the acceptor to the donor [33]. Since the $\mathrm{X}$...H distances are shorter in the X...HOH hydrogen bonds $(\mathrm{X}=\mathrm{N}, \mathrm{O})$ than in the $\mathrm{N}-\mathrm{H}$...O (water) bonds, the former bonds must be stronger and consequently larger amount of charges are to be transferred from the solute to the water molecules than in the opposite direction through the formation of the $\mathrm{N}-\mathrm{H}$... O (water) bonds. The total solute charge is zero for a pure solute in the continuum solvent. The total supermolecule charge is also zero but the net solute charge, due to charge transfers, is generally not zero. Depending on the direction of the net charge transfer, the solute can be both positive and negative, As discussed above, more charge are expected to leave the present solutes than being received from the surrounding water molecules, thus the net solute charge should be positive. Numerical results in Table 2 prove it.

Based on the above numerical values, the tetrahydrate solute charges cannot be utilized in atomic charge parameterization for $\mathrm{MC}$ because an essential requirement is the total zero charge for an explicit-solvent solution model. Table 2 shows that the net solute charge from the tetrahydrate is strongly positive. Since the atomic charges for the applied TIP4P model are fixed and sum up strictly to zero (although the molecule is polarized in comparison with the gas-phase water for producing good density and heat of vaporization for the liquid water [37]), only the charges derived for the pure solute could be used in the present calculations.

By the FEP/MC procedure [38,39], the relative solvation free energy was calculated for different conformational/tautomeric transformations. The results are compared with the corresponding IEF-PCM/B97D (upper row) and IEF-PCM/MP2 (lower row) values in Table 3. The goal of the presented MC calculations is not to completely repeat the corresponding IEF-PCM solvation free energy calculations. Results in Table 3 were intended to point out that consideration of explicit solvent molecules, primarily water molecules would affect the derived $\Delta \mathrm{G}_{\text {solv }}$ due to supposedly account for the thermally averaged solute-water hydrogen bond interactions in the first hydration shell.

Regarding the B97D results in the table, the $\Delta \mathrm{G}_{\text {solv }} / \mathrm{PCM}$ values as calculated by using the aug-cc-pvtz basis set are also provided in parentheses. These values deviate from the corresponding aug-cc-pvqz values within the rounding error. Thus the difference of the MP2/aug-cc-pvtz and B97D/aug-cc-pvtz $\Delta \mathrm{G}_{\text {solv }} / \mathrm{PCM}$ values should be attributed to the applied method, just like for $\Delta \mathrm{E}^{\mathrm{s}}$ int as discussed above.

The FEP/MC simulations utilized the IEF-PCM/B97D/aug-cc-pvqz molecular electrostatic potential fitted charges. The calculated $\Delta \mathrm{G}_{\text {solv }}$ values for the s-trans/anti to syn conformational change (1 to 2) by the IEF-PCM and MC methods are close in aqueous solution, suggesting that the solute is similarly well exposed to hydration, and formation of solute-water hydrogen bonds are favored in both conformations (Table 4). For other conformer pairs, however, the situation is apparently largely different. For (7) vs. (5) and (13) vs. (12), the possible intramolecular hydrogen bond (see for the discussions above) must strongly reduce the solute's capacity for forming solute-solvent hydrogen bonds and the MC value is then largely increased. Tautomeric change to structure (9) is not supported in any solvent by any method. The MC result is outstandingly unfavorable in water. In contrast, aqueous solvations of (8) and (15) are highly favored at any level, even though the MC values are 
remarkably less negative than those from IEF-PCM. The structural basis for the favorable solvation is that the anti HNCC arrangement allows favorable hydration of the $\mathrm{N}-\mathrm{H}$ bonds, whereas the nitrogen lone pairs are also open to accept a hydrogen bond with a nearby water molecule. The O...N and $\mathrm{N}$... N distances are 285 and $290 \mathrm{pm}$ in (8) and (15), respectively. There is room enough for locating 1-2 hydrogen bond donor water molecules. Nonetheless, $\Delta \mathrm{E}^{\mathrm{s}}$ int is too high for each of these species and prevents their appearance in an aqueous solution

Table 3. IEF-PCM and FEP/Monte Carlo relative solvation free energies, $\Delta \mathrm{G}_{\text {solv }}{ }^{\mathrm{a}}$.

\begin{tabular}{|c|c|c|c|c|}
\hline \multirow{2}{*}{ For Transformation } & \multicolumn{2}{|c|}{ Dichloromethane } & \multicolumn{2}{|c|}{ Water } \\
\hline & IEF-PCM & MC & IEF-PCM & MC \\
\hline \multicolumn{5}{|l|}{$\mathrm{CH}_{2}=\mathrm{CH}-\mathrm{CH}=\mathrm{NH}$} \\
\hline $\mathbf{1}$ to $\mathbf{T S}$ (toward 2) & $7.8(7.8)$ & $5.1 \pm 0.1$ & & \\
\hline \multirow[t]{2}{*}{1 to 2} & $-1.8(-1.8)$ & $-1.2 \pm 0.2$ & $-2.0(-2.1)$ & $-1.6 \pm 0.3$ \\
\hline & -2.1 & & -2.3 & \\
\hline \multicolumn{5}{|l|}{$\mathrm{O}=\mathrm{CH}-\mathrm{CH}=\mathrm{NH}$} \\
\hline \multirow[t]{2}{*}{5 to 7} & $0.4(0.4)$ & $1.4 \pm 0.5$ & $0.2(0.3)$ & $9.5 \pm 0.9$ \\
\hline & -1.9 & & -3.0 & \\
\hline \multirow[t]{2}{*}{5 to 8} & & & $-14.9(-14.8)$ & $-9.0 \pm 0.3$ \\
\hline & & & -22.3 & \\
\hline \multirow[t]{2}{*}{5 to 9} & $7.4(7.4)$ & $5.7 \pm 0.2$ & $8.2(8.2)$ & $14.1 \pm 0.4$ \\
\hline & 9.2 & & 10.3 & \\
\hline \multicolumn{5}{|l|}{$\mathrm{HN}=\mathrm{CH}-\mathrm{CH}=\mathrm{NH}$} \\
\hline \multirow[t]{2}{*}{$\mathbf{1 0}$ to 11} & $-3.4(-3.3)$ & $-0.8 \pm 0.3$ & $-4.8(-4.8)$ & $-0.1 \pm 0.4$ \\
\hline & -5.0 & & -6.8 & \\
\hline \multirow[t]{2}{*}{10 to 12} & & & $-4.8(-4.8)$ & $2.6 \pm 0.4$ \\
\hline & & & -7.1 & \\
\hline $\mathbf{1 0}$ to $\mathbf{T S}$ (toward $\mathbf{1 5}$ ) & & & $-9.8(-9.8)$ & $-3.1 \pm 0.2$ \\
\hline \multirow[t]{2}{*}{10 to 15} & & & $-18.5(-18.6)$ & $-9.4 \pm 0.4$ \\
\hline & & & -24.4 & \\
\hline \multirow[t]{2}{*}{12 to 13} & $2.1(2.1)$ & $4.5 \pm 0.3$ & $2.5(2.5)$ & $10.2 \pm 0.5$ \\
\hline & 0.4 & & 0.9 & \\
\hline
\end{tabular}

a Values in kJ/mol. IEF-PCM: upper row B97D/aug-cc-pvqz (aug-cc-pvtz values in parentheses), lower row MP2/aug-cc-pvtz values.

Table 3 shows that the calculated B97D and the average MC relative solvation free energies differ by $0.6-2.7 \mathrm{~kJ} / \mathrm{mol}$ in dichloromethane and the $\Delta \mathrm{G}_{\text {solv }}$ signs always agree. The difference scatters between 0.4 and $9.3 \mathrm{~kJ} / \mathrm{mol}$ for aqueous solutions and the signs calculated by the two methods agree in all cases but for $\Delta \mathrm{G}_{\text {solv }}$ (10) to (12). This result, $2.6 \pm 0.4$ makes the relative free energy of the s-trans/syn/syn conformer much less stable than calculated for the pure solute; $\Delta \mathrm{G}_{\text {tot }}$ of $1.7 \mathrm{~kJ} / \mathrm{mol}$ from Table 1 increases to $9.1 \mathrm{~kJ} / \mathrm{mol}$. The result predicts only a small fraction for the $s$-trans $/ \mathrm{syn} / \mathrm{syn}$ 1,2-diiminoathane conformer (12) in aqueous solution. The FEP/MC value is $-0.1 \pm 0.4$ for the (10) to (11) transformation and would be $-1.3 \mathrm{~kJ} / \mathrm{mol}$ at the lower limit at the $3 \mathrm{SD}$ (99\%) level, which is not enough to stabilize (11) relative to (10). $\Delta \mathrm{G}_{\text {tot }}$ of $-1.3 \mathrm{kcal} / \mathrm{mol}$ from Table 1 increases to $2.2 \mathrm{~kJ} / \mathrm{mol}$ on the basis of the MC calculations. A relative free energy of $2.2 \mathrm{~kJ} / \mathrm{mol}$ corresponds to (11): (10) ratio of 29:71 at room temperature. 
Table 4. Coordination numbers $(\mathrm{CN})$ and number of hydrogen bonds $(n \mathrm{HB})$ in aqueous solution ${ }^{\mathrm{a}}$.

\begin{tabular}{|c|c|c|c|c|c|c|c|c|c|}
\hline Structures in Schemes & $\mathbf{O} / \mathbf{O}_{\mathrm{w}}$ & $\mathbf{O} / \mathbf{H}_{\mathrm{w}}$ & $\mathbf{N}_{\mathrm{t}} / \mathbf{O}_{\mathrm{w}}$ & $\mathrm{N}_{\mathrm{t}} / \mathrm{H}_{\mathrm{w}}$ & $\mathbf{N}_{\mathrm{c}} / \mathbf{O}_{\mathrm{w}}$ & $\mathbf{N}_{\mathrm{c}} / \mathbf{H}_{\mathrm{w}}$ & $(\mathrm{N}) \mathrm{H}_{t} / \mathbf{O}_{\mathrm{w}}$ & $(\mathbf{N}) \mathbf{H}_{\mathrm{c}} / \mathbf{O}_{\mathrm{w}}$ & $n_{\mathrm{HB}}{ }^{\mathrm{b}}$ \\
\hline $\mathrm{CH}_{2}=\mathrm{CH}-\mathrm{CH}-\mathrm{NH}(\mathbf{1})$ & & & 3.4 & 2.0 & & & 0.9 & & $2.3(-3.0)^{\mathrm{c}}$ \\
\hline $\mathrm{CH}_{2}=\mathrm{CH}-\mathrm{CH}-\mathrm{NH}(\mathbf{2})$ & & & 3.1 & 2.1 & & & 0.8 & & $2.4(-3.0)^{\mathrm{c}}$ \\
\hline $\mathrm{O}=\mathrm{CH}-\mathrm{CH}=\mathrm{NH}(\mathbf{5})$ & 1.4 & 1.3 & 2.5 & 1.3 & & & 1.0 & & $2.9(-3.0)$ \\
\hline $\mathrm{O}=\mathrm{CH}-\mathrm{CH}=\mathrm{NH}(7)$ & $-d$ & 1.1 & & & 2.0 & 1.0 & & 0.8 & $1.4(-3.5)^{\mathrm{c}}$ \\
\hline $\mathrm{O}=\mathrm{CH}-\mathrm{CH}=\mathrm{NH}(\mathbf{8})$ & 1.9 & 1.5 & & & 2.8 & 1.3 & & 1.0 & $3.0(-3.5)$ \\
\hline $\mathrm{O}=\mathrm{C}=\mathrm{CH}-\mathrm{NH}_{2}(\mathbf{9})$ & $-d$ & $0.6^{\mathrm{e}}$ & $-d$ & 1.0 & & & 0.7 & & $2.3(-2.5)^{\mathrm{c}}$ \\
\hline $\mathrm{HN}=\mathrm{CH}-\mathrm{CH}=\mathrm{NH}(\mathbf{1 0})$ & & & 2.8 & 1.5 & & & 0.8 & & $3.9(-3.0)$ \\
\hline $\mathrm{HN}=\mathrm{CH}-\mathrm{CH}=\mathrm{NH}(\mathbf{1 1})$ & & & $2.9,3.1$ & $1.3,1.7$ & & & $1.0,1.0$ & & $4.4(-3.0)$ \\
\hline $\mathrm{HN}=\mathrm{CH}-\mathrm{CH}=\mathrm{NH}(\mathbf{1 2})$ & & & 3.0 & 1.5 & & & 0.95 & & $4.1(-3.0)$ \\
\hline $\mathrm{HN}=\mathrm{CH}-\mathrm{CH}=\mathrm{NH}(\mathbf{1 3})^{\mathrm{f}}$ & & & & & $2.1,2.7$ & $1.3,1.0$ & & $0.4,0.95$ & $2.6(-3.0)$ \\
\hline TS (from 10 toward 15) ${ }^{\mathrm{f}}$ & & & 3.2 & 1.6 & & & & 1.0 & $4.3(-3.0)$ \\
\hline $\mathrm{HN}=\mathrm{CH}-\mathrm{CH}=\mathrm{NH}(\mathbf{1 5})^{\mathrm{g}}$ & & & & & 2.9 & 1.6 & & 1.0 & $4.7(-2.5)$ \\
\hline
\end{tabular}

${ }^{a}$ For species 9, the nitrogen/X CN values appear with subscript " $t$ ", for 11 and 13 coordination numbers refer to nitrogens from the left to right in Scheme 2. Integration limits: $305 \mathrm{pm}\left(\mathrm{O} / \mathrm{O}_{\mathrm{w}}\right), 240-255 \mathrm{pm}\left(\mathrm{O} / \mathrm{H}_{\mathrm{w}}\right)$, 325-355 pm (N/O $\left.\mathrm{w}_{\mathrm{w}}\right), 245-260 \mathrm{pm}\left(\mathrm{N} / \mathrm{H}_{\mathrm{w}}\right), 235-255 \mathrm{pm}\left(\mathrm{H} / \mathrm{O}_{\mathrm{w}}\right) ;{ }^{\mathrm{b}}$ Integration limit of the pedf in parentheses; ${ }^{\mathrm{c}}$ No resolved first peak below $350 \mathrm{pm}$; ${ }^{\mathrm{d}}$ Middle of a plateau; ${ }^{\mathrm{e}}$ End of a plateau at $225 \mathrm{pm}$; ${ }^{\mathrm{f}}$ First and second $\mathrm{CN}$ values for the right-hand and the left-hand side $\mathrm{N}-\mathrm{H}$ atoms, respectively; and ${ }^{\mathrm{g}}$ Equivalent nitrogens in gauche position.

Since in any case but one the signs for $\Delta \mathrm{G}_{\text {solv }}$ have been preserved when the IEF-PCM/B97D and the $\mathrm{MC}$ values are compared, consideration of the $\Delta \mathrm{G}_{\text {solv }} / \mathrm{MC}$ values would not modify the $\Delta \mathrm{G}_{\text {tot }}$ results qualitatively as obtained by IEF-PCM (not even for (12)). In other words, the MC studies do not lead to the reversal of the preferred structure for the studied pairs. For the $s-c i s \mathrm{O}=\mathrm{CH}-\mathrm{CH}=\mathrm{NH}$ conformer (7), even the IEF-PCM study predicted a fraction of only about 3\% in the equilibrium composition in aqueous solution (whereas there is about 32\% (6) also present as calculated from IEF-PCM values). On the basis of the $\mathrm{MC}$ results, the fraction must be further reduced. Each of the relative $\Delta \mathrm{E}^{\mathrm{s}}$ int and $\Delta \mathrm{G}_{\text {solv }}$ is so much positive for $\mathrm{O}=\mathrm{C}=\mathrm{CH}-\mathrm{NH}_{2}$ (9) in both solvents (Table 1) that this tautomer would not appear in the solution except if the kinetic control is in effect (see next section). For conformer (13), its fraction relative to the most stable (10) s-trans form is about 3\%-5\% in both solvents upon the IEF-PCM calculations. On the basis of the FEP/MC simulations, this fraction practically disappears in solution. Thus each of the two models predicts small, possibly negligible fractions even for the most stable s-cis conformations in the studied solutions.

\subsection{Solution Structures}

By utilization of the MC simulation results, some structural characteristics of the considered species in aqueous solution are summarized in Table 4 . The coordination numbers $(\mathrm{CN})$ were calculated by integration of the radial distribution functions (rdf) [40] up to their first minima, as indicated in the footnote of the table. The sites of the first minima scatter within a few tens of a pm. The $n_{\mathrm{HB}}$ values were obtained by integration of the solute-solvent pair-energy distribution functions (pedf) up to their first minima or until the middle of a plateau. According to Jorgensen et al. [37], $n \mathrm{HB}$ may be considered as the number of the solute-solvent intermolecular hydrogen bonds in a protic solvent. 
The $\mathrm{CN}$ and $n \mathrm{HB}$ values are very similar for the anti (1) and syn (2) $s$-trans $\mathrm{CH}_{2}=\mathrm{CH}-\mathrm{CH}-\mathrm{NH}$ conformers. The slightly larger $n \mathrm{HB}$ number for the syn form and its dipole moment of $3.5 \mathrm{D}$ vs $2.9 \mathrm{D}$ for the anti form, calculated from point charges, are in accord with the $-1.5 \mathrm{~kJ} / \mathrm{mol}$ for $\Delta \mathrm{G}_{\text {solv }}$ by $\mathrm{MC}$. The B97D exact dipole moments are 3.6 and 3.0 D, respectively. In general, the point-charge-based dipole moments reproduced the exact values (Table S1) generally within $0.2 \mathrm{D}$ for the studied species.

While hydration characteristics of the s-trans/anti (5) and s-cis/anti (8) (for which conformers tetrahydrates were also investigated in Figure 1) are rather similar, coordination numbers for $s$-cis/syn (7) 2-imino-acetaladehyde and for the amino-ketene tautomer (9) are rather different. The first solvation sphere around the carbonyl oxygen is well defined for (5) and (8) with $\mathrm{O} / \mathrm{O}_{\mathrm{w}}$ coordination numbers of 1.4-1.9. Comparing the $\mathrm{O} / \mathrm{O}_{\mathrm{w}}$ and $\mathrm{O} / \mathrm{H}_{\mathrm{w}} \mathrm{CN}$ values for (5), the $\mathrm{CN}$ 's are nearly equal suggesting that every solvating water molecule forms one hydrogen bond pointing toward the carbonyl oxygen. $\mathrm{O} / \mathrm{H}_{\mathrm{w}}$ is less by 0.4 units than $\mathrm{O} / \mathrm{O}_{\mathrm{w}}$ for (8), suggesting that not all surrounding waters form hydrogen bonds with the carbonyl oxygen. This is in good accord with the $8 \mathrm{cA}$ tetrahydrate structure prediction in Figure 1, where water 2 is bound to water 1 instead of forming a $=\mathrm{O} \ldots \mathrm{H}_{\mathrm{w} 21} \mathrm{O}_{\mathrm{w} 2}$ hydrogen bond. No resolved $\mathrm{O} / \mathrm{O}_{\mathrm{w}}$ peaks were noted, however, for the other two $\mathrm{C}_{2} \mathrm{H}_{3} \mathrm{NO}$ species. There is an intramolecular hydrogen bond in the s-cis conformer (7) and whereas the nitrogen can act as a full hydrogen-bond acceptor $\left(\mathrm{N}_{\mathrm{c}} / \mathrm{H}_{\mathrm{w}}=1.0\right)$, the $(\mathrm{N})_{\mathrm{c}} \mathrm{H}$ proton can only partially act as a hydrogen-bond donor to a water oxygen as concluded from $(\mathrm{N})_{\mathrm{c}} \mathrm{H} / \mathrm{O}_{\mathrm{w}}$ coordination number of 0.8 , thus less than 1 for a full hydration. As a consequence, the $n_{\mathrm{HB}}$ value decreased from 2.9 for (5) to 1.4 for (7). Although the dipole moment is slightly larger for the latter (Supplementary Table S1), the relative solvation free energy is remarkably positive, $9.5 \pm 0.9 \mathrm{~kJ} / \mathrm{mol}$ from MC simulations, probably due to the smaller number of the hydrogen bonds. The $\mathrm{O} / \mathrm{H}_{\mathrm{w}} \mathrm{CN}$ for the ketene oxygen (9) is considerably smaller, 0.6 compared with 1.3 for (5), indicating a less strictly localized solvent sphere at this site. In contrast, the $\mathrm{N}_{\mathrm{t}} / \mathrm{H}_{\mathrm{w}}$ as well as the $(\mathrm{N}) \mathrm{t} / \mathrm{H} / \mathrm{O}_{\mathrm{w}}$ coordination numbers for the two tautomers are much closer to each other, suggesting no basic hydration difference for the $=\mathrm{NH}$ and the $-\mathrm{NH}_{2}$ groups. There are 1.0-1.3 water hydrogens around the nitrogen atoms for (5) and (9), which can form strong $\mathrm{N}_{\text {.... }} \mathrm{H}_{\mathrm{w}} \mathrm{O}_{\mathrm{w}}$ hydrogen bonds. Overall, the reduced $n_{\mathrm{HB}}$ number relative to that for (5) and the remarkably smaller dipole moment for (9) support the calculated $\Delta \mathrm{G}_{\text {solv }}$ of $14.1 \pm 0.4 \mathrm{~kJ} / \mathrm{mol}$.

The $\mathrm{HN}=\mathrm{CH}-\mathrm{CH}=\mathrm{NH}$ s-trans $(10)$ and (12) conformers have a $\mathrm{C}_{2 \mathrm{~h}}$ symmetry, whereas conformers (11) and (13) have only a $\mathrm{C}_{\text {s }}$ symmetry. The $\mathrm{CN}$ values (subscript " $\mathrm{t}$ " for (10-12) and "c" for (13)) must be very close for the equivalent nitrogens and hydrogens in structure (10) if statistical fluctuation is accepted (only the average of the almost equal individual values are presented). The same expectations apply for (12). The $\mathrm{N}-\mathrm{H}$ groups are not identical in (13), for this species two values are presented. For conformers (10-12), the nitrogen atoms are open to hydration by water at their lone pair regions, and the imine hydrogens are also easily reachable by water oxygens. All these hydration patterns can assure formations of $\mathrm{N} \ldots . \mathrm{H}_{\mathrm{w}} \mathrm{O}_{\mathrm{w}}$ and $\mathrm{N}-\mathrm{H} \ldots \mathrm{O}_{\mathrm{w}}$ intermolecular hydrogen bonds. For conformer (13), the $\mathrm{N}_{\mathrm{c}} / \mathrm{O}_{\mathrm{w}}$ and the $(\mathrm{N})_{\mathrm{c}} \mathrm{H} / \mathrm{O}_{\mathrm{w}}$ values differ considerably from the corresponding $\mathrm{N}_{\mathrm{t}}$ CNs. The differences stem from the deviations in the hydration abilities of the two imine groups. The right-hand side, syn $\mathrm{NH}$ group of (13) can form a strongly bent intramolecular hydrogen bond with the left-hand side (anti HN) nitrogen lone pair (Scheme 2). This bond reduces the hydration capacity of the molecule in the top region, but allows for favorable $\mathrm{N} . . . \mathrm{H}_{\mathrm{w}} \mathrm{O}_{\mathrm{w}}$ bond formation at the right-hand side $(\mathrm{CN}=1.3)$ and the $(\mathrm{N}) \mathrm{H} \ldots \mathrm{O}_{\mathrm{w}}$ hydration on the left-hand side $(\mathrm{CN}=0.95)$. The reduced exposure of 
(13) to hydration, as revealed from the sum of the $\mathrm{N}_{\mathrm{c}} / \mathrm{O}_{\mathrm{w}}$ values in comparison with the double of the $\mathrm{N}_{\mathrm{t}} / \mathrm{O}_{\mathrm{w}}$ coordination number for structures (10) and (12) and with the sum of the $\mathrm{N}_{\mathrm{t}} / \mathrm{O}_{\mathrm{w}}$ values for (11) necessarily leads to the decrease of the $n \mathrm{HB}$ value by 1.3-1.8 units for the $s$-cis conformer compared to that for the (10-12) s-trans forms.

\subsection{Equilibration Mechanism}

Equilibration of some conformers is possible both in the gas phase and in the studied solvents by rotation about the central $\mathrm{C}-\mathrm{C}$ bond because the calculated barrier heights are moderate. The studied pairs meeting the conditions are $(1,3),(2,4),(5,8),(6,7),(10,15),(11,13)$ and $(12,14)$. The calculated $\Delta \mathrm{G}_{\text {tot }}^{\mathrm{s}}$ values are, however, so large for $(3,4,7,8,13-15)$ that the s-cis conformers could be hardly observed experimentally. The intramolecular transformation for the pair $(1,2)$ was found as proceeding along $\mathrm{H}$ rotation about the $\mathrm{C}=\mathrm{N}$ bond followed by $\mathrm{N}$-inversion, for which the activation energy was calculated at about $111 \mathrm{~kJ} / \mathrm{mol}$ in solution for (2) (Table 1).

In a dilute aqueous solution, small polar molecules could be dissolved in monomeric form at least at a large fraction. For monomers, the $\mathrm{CC}=\mathrm{NH}$ anti to syn transformation must be feasible by water catalysis if the favorable hydration of structures of (1), (5), and (10-12) are considered (Table 4). More directly, conclusions from the tetrahydrate structures could be drawn (Figure 1). The water molecule w3 can donate a hydrogen and forms an $\mathrm{N} . . . \mathrm{H}_{\mathrm{w} 31}-\mathrm{O}_{\mathrm{w} 3}$ hydrogen bond, whereas the w4 water molecule forms an $\mathrm{N}-\mathrm{H}$... $\mathrm{O}_{\mathrm{w} 4}$ intermolecular hydrogen bond. The anti/syn transformation would be carried out by the $\mathrm{H}_{\mathrm{w} 31}$ jump over to the nitrogen, whereas it releases its covalently bound proton toward $\mathrm{O}_{\mathrm{w} 4}$. Along a sequential mechanism, a solute-solvent ion-pair is formed, irrespective of the actual proton involved in the first proton jump. The system's status after the first proton jump will be, however, different. If $\mathrm{H}_{\mathrm{w} 32}$ jumps first, the solute will be protonated facing an $\mathrm{OH}^{-}$anion. If the $\mathrm{N}-\mathrm{H}$ proton leaves first (less likely, since imines are not strong acids), a negatively charged solute anion and a hydroxonium cation form an ion-pair. In any case, the ion-pair could be stabilized in water for a short time until the second proton jump takes place. Now the solute is neutral, whereas there is a $\mathrm{O}_{\mathrm{w} 3} \mathrm{H}_{\mathrm{w} 32}$ hydroxyl anion and a $\mathrm{HO}_{\mathrm{w}} 4 \mathrm{H}_{2}$ hydroxonium cation. The water molecules are members of a water network. Either in a concerted mechanism or through a sequential process, a double proton-relay results in the anti to syn transformation [10] and the neutralization of the hydroxyl-hydroxonium ion-pair will be reached by proton jumps along the water chain connecting $\mathrm{O}_{\mathrm{w} 3}$ and $\mathrm{O}_{\mathrm{w} 4}$. Calculated coordination and hydrogen-bond numbers are in conformity with this supposed mechanism. The outlined equilibration mechanism for the $(1,2)$ and $(5,6)$ pairs is a reasonable alternative of the $\mathrm{H}$ rotation about the $\mathrm{C}=\mathrm{N}$ bond followed by an $\mathrm{N}$-inversion in aqueous solution. This mechanism must fail, however, in a non-protic solvent like dichloromethane. In that solvent, equilibration may proceed along an alternative route, namely through solute association.

$\mathrm{N}-\mathrm{H}$ containing molecules could produce $(\mathrm{N}-\mathrm{H})_{n}$ rings with $\mathrm{Nlp} \ldots \mathrm{H}-\mathrm{N}$ bonds, where $1 \mathrm{p}$ stands for the nitrogen lone pair. Formation of a three-member ring was found experimentally even in the gas phase [41]. Through concerted proton jumps in a dimer, the syn conformer could come into existence. Polar solute association may be favored in a non-protic solvent, which supports the formation of intermolecular hydrogen bonds for the polar sites. Strong dimerization was found for acetic acid in chloroform [10] and for pyruvic acid in dichloromethane [1]. 
IEF-PCM/B97D/aug-cc-pvtz geometry optimization for an s-trans $\mathrm{CH}_{2}=\mathrm{CH}-\mathrm{CH}=\mathrm{NH}$ dimer (18) (Scheme 3) in dichloromethane predicted individually planar monomers with $\mathrm{C}=\mathrm{N} \ldots \mathrm{N}=\mathrm{C}$ torsion angle of $42^{\circ}$ at $323 \mathrm{pm} \mathrm{N}$... N distance. One intermolecular hydrogen bond was noticed with N...H distance of $225 \mathrm{pm}$ and $\mathrm{N}-\mathrm{H} . . . \mathrm{N}$ bond angle of $157^{\circ}$. The other N...H distance was determined as $391 \mathrm{pm}$.

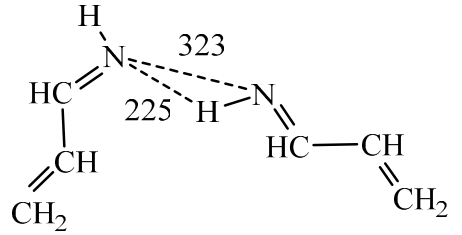

18

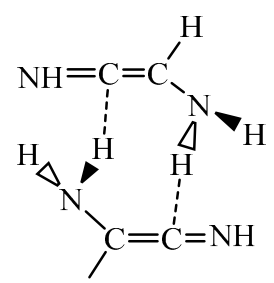

20

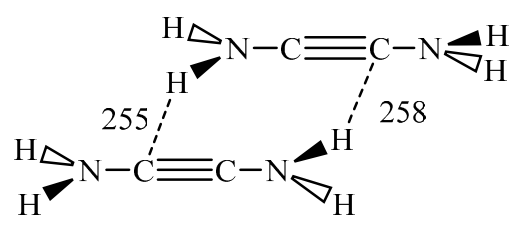

19

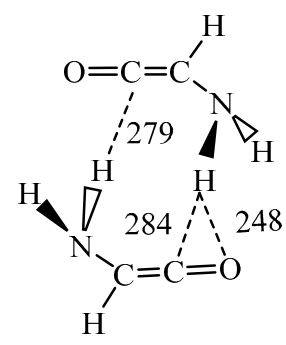

21

Scheme 3. IEF-PCM/B97D/aug-cc-pvtz optimized s-trans 2-propene-imine dimer (18) in dichloromethane. $\mathrm{N}-\mathrm{H} \ldots \mathrm{N}$ angle $157^{\circ}, \mathrm{C}=\mathrm{N} \ldots \mathrm{N}=\mathrm{C}$ torsion angle $41.2^{\circ}$. 2-diamino acetylene dimer, optimized in the gas phase (19). Schematic structure of the 2-amino imino-ketene dimer (20). 2-amino ketene dimer, optimized in dichloromethane (21). Dashed lines indicate selected interatomic distances in $\mathrm{pm}$.

The potential of mean force curve (pmf) is shown in Figure 2 for a pair of the (1) species in dichloromethane. The free energy of the system (with $\mathrm{G}=0$ at $\mathrm{N} \ldots \mathrm{N}$ separation of $1200 \mathrm{pm}$ ) has a maximum of $1.4 \pm 0.3 \mathrm{~kJ} / \mathrm{mol}$ at $\mathrm{R}(\mathrm{N} \ldots \mathrm{N})=570 \mathrm{pm}$, becomes negative below $\mathrm{R}=350 \mathrm{pm}$ and reaches its minimum of $-3.8 \pm 0.4 \mathrm{~kJ} / \mathrm{mol}$ with $\mathrm{N} \ldots \mathrm{N}$ separation of $300 \mathrm{pm}$.

The solution concentration is about 0.12 molar corresponding to two moles of solutes in a total volume of $17 \mathrm{dm}^{3}$. Assuming a small cube as its own volume for a solute, in the case of a uniform local solute density when the reference solute atoms reside at the centers of the cubes, their distances to the nearest neighbors are at about $2400 \mathrm{pm}$ in a 0.12 molar solution. Thermal effects destroy this ordered arrangement, and as the calculated pmf shows, a fraction of the molecules tends to associate. The ratio of the integrals of the $\mathrm{R}^{2} \exp (-\Delta \mathrm{G} / R T)$ curve in the ranges of $\mathrm{R}(0, \mathrm{R}(\mathrm{spec}))$ and $\mathrm{R}(0-2400)$ $\mathrm{pm}$ provides the fraction of the associated dimer relative to all other dimer arrangements [42]. Here, $\mathrm{R}$ (spec) is an appropriately chosen N...N separation, which was accepted as $570 \mathrm{pm}$ in the present calculation, corresponding to the site of the top of the association barrier. $G$ was accepted as maintaining the reference value $(\mathrm{G}=0)$ at $\mathrm{R}>1200 \mathrm{pm}$. The calculated total associated fraction was slightly more than $1 \%$, but is much less than that in the $N$...N separation range of 300-320 pm required for the formation of a hydrogen-bond within the dimer. 


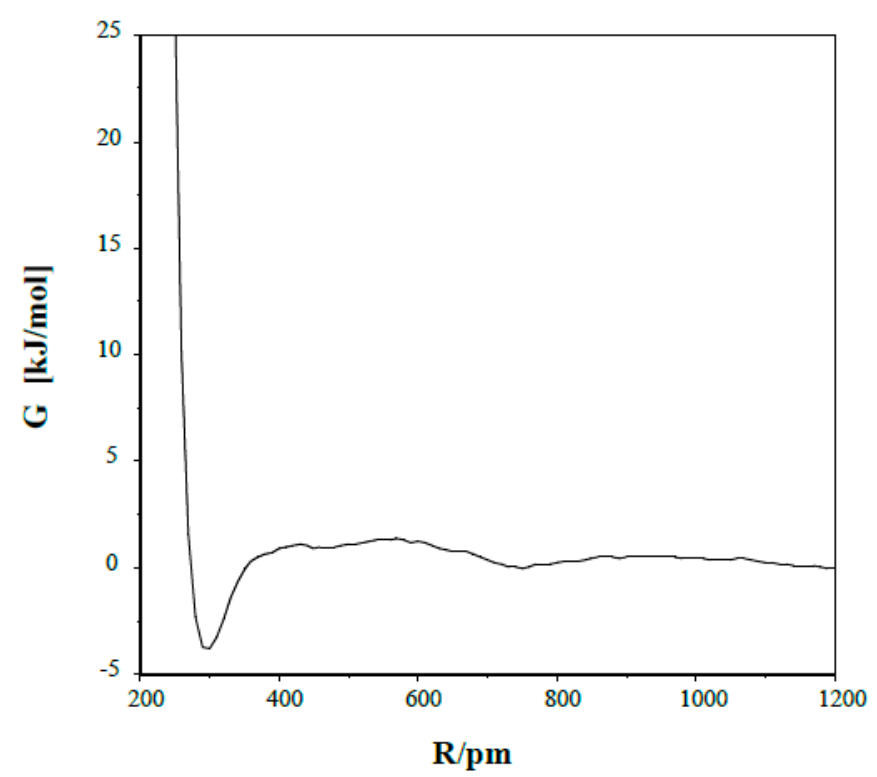

Figure 2. Potential of mean force for the $s$-trans/anti dimer in dichloromethane.

Upon inspection of some snapshots through MC simulations, arrangements with one, primarily linear $\mathrm{N}-\mathrm{H}$... $\mathrm{N}$ hydrogen bond was found for the dimer at the minimum $(\mathrm{R}=300 \mathrm{pm})$ of the pmf. This orientation is not far from the calculated optimal dimer structure and is not favorable for a double proton-relay. Although the thermal motion may lead to some bent $\mathrm{N}-\mathrm{H} \ldots \mathrm{N}$ structure, a prerequisite for forming another hydrogen bond, the pmf does not support the concerted double proton-relay. Jump over of a single proton would result in formation of an ion-pair temporarily, whose stabilization by a moderately polar solvent like $\mathrm{CH}_{2} \mathrm{Cl}_{2}$ is questionable. Thus the idea of a collision-based $\mathrm{H}$ rotation about the $\mathrm{C}=\mathrm{N}$ bond/ $\mathrm{N}$-inversion is left in the dicholoromethane solvent.

Exploration of the tautomerization mechanism for $\mathrm{H}_{2} \mathrm{~N}-\mathrm{C} \equiv \mathrm{C}-\mathrm{NH}_{2}$ (17) is also a complicated problem. Geometry optimization in the gas phase predicts linear arrangement for the heavy atoms, whereas the rotational positions of the two amino groups break any symmetry for the molecule. In fact, two optical antipodes are possible, and no easily reachable path is available for an intramolecular 1,3 hydrogen relocation, which would lead to the formation of the $\mathrm{HN}=\mathrm{C}=\mathrm{CH}-\mathrm{NH}_{2}$ tautomer (Scheme 2).

By studying dimeric structures (19-21, Scheme 3), possibilities for their tautomerizations were investigated. As calculated at the B97D/aug-cc-pvtz level in the gas phase (for calculation details, see [10]), only about $1 \%$ of the (19) monomers form a dimer. Concerted double proton-relay is unlikely along the two weak N-H...C hydrogen bonds. A sequential mechanism may be even less likely, because the formed ion-pair could be hardly stabilized in the gas phase. Considering the above experience with the pmf calculations, even dichloromethane may not have the satisfactory stabilizing effect to facilitate either the tautomeric transformation of (19) to (20) or the transformation of the (20) dimer to yield the dimer of some of (10-12).

Structure (21) shows the intermolecular hydrogen bond pattern calculated for the optimized amino ketene dimer in dichloromethane. The structure suggests that the $\mathrm{N}-\mathrm{H}$... O hydrogen bond must be stronger than any of the $\mathrm{N}-\mathrm{H}$...C hydrogen bonds in the dimer. Accordingly, if a proton jumps to the carbonyl oxygen, then the formed structure with an $\mathrm{OH}$ group will definitely differ from structures (5-8). This structure may later reorganize, but this reaction path strongly suggests that tautomerization 
of the studied systems in the gas phase and in non-polar solvents may not proceed via one-step double proton-relay mechanism.

An alternative is that the kinetic control is in effect regarding the tautomerization of the present systems. The ketenes (and possibly imino-ketenes) are stable in a non-aqueous solution [12]. The calculations have found that the (9) and (16) structures correspond to local minima on the potential energy hypersurface in solution. If they were prepared in some non-aqueous solvent they may not convert to the corresponding most stable (5) and (10) structures according to the above discussion. Adding, however, even a catalytic amount of water to the solution, a provision of a proton to the carbon involved in cumulated double bonds and a drop-off of a proton at the $\mathrm{NH}_{2}$ site could be a feasible process. The waters are in a water network again, and the neutralization of the formed ion-pair would easily proceed through a number of proton jumps along the water bridge.

\section{Methods and Calculations}

The theoretical approaches for the present analyses follow mainly the procedures described previously [10,22,23]. Calculations were performed using the DFT/B97D method of Grimme [26] and the $\operatorname{CCSD}(\mathrm{T})$ energies were extrapolated to the complete basis set limit (CBS) by utilizing the G09 package [43] implemented at the Ohio Supercomputer Center. Both the gas-phase and solute geometries were optimized using the aug-cc-pvtz basis set [44-46] by the B97D method and at MP2 where applied. Local energy minima were certified with all positive vibrational frequencies calculated generally with B97D. All geometry optimizations were conducted without symmetry restrictions. In order to avoid an artificial trap into some local planarity, all torsion angles anticipated as of $0^{\circ}$ and $180^{\circ}$ were set to some values deviating from the target value by $1^{\circ}-2^{\circ}$ in the starting geometries. Optimization could then reach an optimal, largely different value or would return to about $0^{\circ}$ and $180^{\circ}$. Perfect local planarity is not expected from such starting geometries through symmetry unrestricted optimizations, thus predicted optimal torsion angles, when the standard optimization criteria were used in Gaussian 09, could slightly differ from $0^{\circ}$ and $180^{\circ}$. No significance was paid to deviations up to $0.2^{\circ}$. With larger values two antipodes have to be considered, whose mixing would result in $-R T \ln 2=-1.717 \mathrm{~kJ} / \mathrm{mol}$ entropy change; see detailed geometry parameters in Supplementary Table S1. For solutions, geometries of the tautomers and conformers (Schemes 1 and 2) were optimized by means of the IEF-PCM approach (integral equation formalism of the polarizable continuum method) $[47,48]$.

The relative free energy for a pair of tautomers/conformers in solution was calculated as:

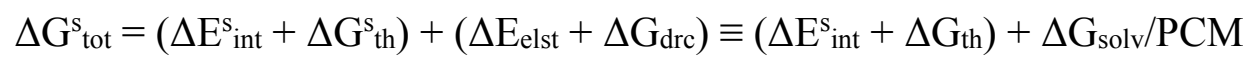

where the terms $\Delta \mathrm{E}^{\mathrm{s}}$ int $+\Delta \mathrm{G}_{\text {th }}^{\mathrm{s}}$ stand for the relative internal energy and the thermal corrections, respectively. The final $\Delta \mathrm{E}^{\mathrm{s}}$ int values were accepted on the basis of $\mathrm{B} 97 \mathrm{D} /$ aug-cc-pvqz single-point calculations in DFT calculations. The thermal corrections were calculated in the rigid rotor-harmonic oscillator approach [49]. $\Delta \mathrm{E}_{\mathrm{elst}}$ and $\Delta \mathrm{G}_{\mathrm{drc}}$ account for the relative solute-solvent electrostatic interaction energy and the relative dispersion-repulsion-cavitation free energy, respectively. The dielectric constants of the dichloromethane and water solvents were set to 8.93 and 78.39 , respectively, and scaled Bondi radii $[31,50]$ were accepted for carving the cavity for polar solute atoms. 
Relative $\operatorname{CCSD}(\mathrm{T})$ in-solution internal energies at the complete basis set limit (CBS) were calculated by using the formula of Hobza [51]:

$$
\Delta \mathrm{E}^{\mathrm{CCSD}(\mathrm{T})}{ }_{\mathrm{CBS}}=\Delta \mathrm{E}^{\mathrm{MP2}} \mathrm{CBS}+\left(\Delta \mathrm{E}^{\mathrm{CCSD}(\mathrm{T})}-\Delta \mathrm{E}^{\mathrm{MP2}}\right) \text { aug-cc-pvdz }
$$

where $\Delta \mathrm{E}^{\mathrm{MP} 2} \mathrm{CBS}$ was obtained upon the extrapolation formula of Helgaker, et al. [52] for the complete basis set limit MP2 energy as:

$$
\mathrm{E}^{\mathrm{MP} 2} \mathrm{CBS}=\mathrm{E}(\mathrm{X})-\mathrm{A} / \mathrm{X}^{3}
$$

" $A$ " and then $\mathrm{E}^{\mathrm{MP} 2} \mathrm{CBS}$ in Equation (3) were obtained by single-point calculations using the aug-cc-pvdz $(X=2)$ and aug-cc-pvtz $(X=3)$ basis sets at the aug-cc-pvtz optimized geometries. Relative solvation free energies were obtained at the MP2/aug-cc-pvtz level after IEF-PCM optimization.

Monte Carlo (MC) simulations in dichloromethane and water solvents were performed in the $\mathrm{NpT}$ (isobaric-isothermal) ensemble at $\mathrm{p}=1 \mathrm{~atm}$ and $\mathrm{T}=298 \mathrm{~K}$ [53-55]. Calculations were carried out by using the BOSS 4.8 package [56]. Atomic interaction energies were calculated by means of the all-atom OPLS-AA 12-6-1 pair-potential [57,58] with the 12-6 Lennard-Jones parameters taken from the program's library. By means of the CHELPG procedure [32], the atomic charges for the solutes were fitted to the IEF-PCM/B97D/aug-cc-pvqz molecular electrostatic potential generated by the polarized solute in the continuum solvent.

The solutes were immersed in a box of 506 TIP4P water molecules [37] or in a box of 263 dichloromethane molecules, using the three-point OPLS $\mathrm{CH}_{2} \mathrm{Cl}_{2}$ model [59]. All cutoffs were set to $12 \AA$, preferential sampling and periodic boundary conditions were applied and the long-range electrostatic effects were taken into account by means of the Ewald summation [60,61]. The relative solvation free energy, $\Delta \mathrm{G}_{\text {solv }} / \mathrm{MC}$ for a pair of solutes was calculated by means of the free energy perturbation method (FEP) [38,39]. The solution was equilibrated by allowing the development of 7.5 $\mathrm{M}$ configurations, and another 7.5 $\mathrm{M}$ configurations were utilized for averaging the relative solvation free energy. Solution structure characteristics were obtained by integration of radial distribution functions [40] until their first minima, and by integration of solute-solvent pair-energy distribution functions (pedfs). The integration of a pedf until its first minimum provides the number of solvent molecules strongly bound to the solute. Possible dimerization of the all-trans $\mathrm{CH}_{2}=\mathrm{CH}-$ $\mathrm{CH}=\mathrm{NH}$ species (1) in dichloromethane was followed by calculating the potential of mean force curve. A model solution-box was composed of 259 dichloromethane and two solute molecules, and FEP/MC interaction potential and simulation parameters at $\mathrm{T}=298 \mathrm{~K}$ were accepted as for the single-solute models above. The change of the free energy of the system was calculated in the $R(N \ldots N)$ separation range of $250-1200 \mathrm{pm}$. The incremental $\Delta \mathrm{G}$ (solv) changes were calculated at $\mathrm{R} \pm 10 \mathrm{pm}$ with $\Delta \mathrm{R}$ steps of $20 \mathrm{pm}$. The N...N separation was fixed at each selected reference point. The solutes could move only in tandem, but independent rotations of the component solutes about randomly selected axes through a randomly selected $\mathrm{N}$ atom were allowed. More details were provided in former papers $[1,10]$ and references therein.

\section{Conclusions}

Conformational/tautomeric isomerizations for $\mathrm{C}_{3} \mathrm{H}_{5} \mathrm{~N}, \mathrm{C}_{2} \mathrm{H}_{3} \mathrm{NO}$, and $\mathrm{C}_{2} \mathrm{H}_{4} \mathrm{~N}_{2}$ molecules have been studied in the gas phase, in dichloromethane, and in aqueous solutions. The most stable studied species 
within an indicated composition group adopts a double bond-single bond-double bond structure, called $\mathrm{DSD}$, in the form of $\mathrm{X}=\mathrm{CH}-\mathrm{CH}=\mathrm{Y}$. This paper is a continuation of the study for DSD structures with all combinations of $\mathrm{CH}_{2}$ and $\mathrm{O}$ for $\mathrm{X}$ and $\mathrm{Y}$ [1]. DSD molecules are subject to $s$-trans/s-cis conformational variety with XCCY torsional angles of $180^{\circ}$ and near $0^{\circ}$, respectively. For the present most stable structures with $\mathrm{X}=\mathrm{CH}_{2}, \mathrm{O}, \mathrm{NH}$ and $\mathrm{Y}=\mathrm{NH}$, the $s$-trans conformation is preferred in the gas phase. The preference is based on the internal free energy calculated at the B97D/aug-cc-pvqz and the $\operatorname{CCSD}(\mathrm{T})_{\mathrm{CBS}}$ levels. The two methods predict in accord that the internal free energy is generally considerably lower for the $s$-trans, CCNH anti species than that for any s-cis form. Possibility for the existence of an intramolecular hydrogen bond and its structure-stabilization effect was discussed for the $s$-cis CCNH syn forms.

Transition state barriers for rotation about the central $\mathrm{C}-\mathrm{C}$ bonds are of about $29-36 \mathrm{~kJ} / \mathrm{mol}$, which can be overridden upon collision. For the $\mathrm{C}-\mathrm{C}=\mathrm{N}-\mathrm{H}$ anti to syn conformational equilibration, the calculated route toward the transitions state is a structural change along $\mathrm{H}$ rotation about the $\mathrm{C}=\mathrm{N}$ bond followed by $\mathrm{N}$-inversion. Reaching TS requires $113-123 \mathrm{~kJ} / \mathrm{mol}$ activation energy in the gas phase (about $110 \mathrm{~kJ} / \mathrm{mol}$ in solution) and more than $100 \mathrm{~kJ} / \mathrm{mol}$ activation free energy. Nonetheless, experiments showed that both $s$-trans/anti and syn forms exist in the gas phase at $\mathrm{T}=673 \mathrm{~K}$ [29].

Relative in-solution free energies were calculated in the IEF-PCM, polarizable continuum dielectric solvent approximation, and relative solvation free energies were estimated for a number of transformations by means of the free energy perturbation/Monte Carlo simulations utilizing explicit solvent models. The s-trans/anti form, due to its much lower internal free energy than that for any $s$-cis, remains prevalent, almost exclusively, in condensed phase. In many cases, however, $\Delta \mathrm{G}_{\text {solv }}$ is negative for an s-cis form, but these values are never enough to reverse the conformational predominance. The FEP/MC relative solvation free energy is less negative by $0.6-9.3 \mathrm{~kJ} / \mathrm{mol}$ then the corresponding IEF-PCM $\Delta \mathrm{G}_{\text {solv }}$ value with generally equal sign for the two terms. This means that $\Delta \mathrm{G}^{\mathrm{s}}$ tot becomes more positive when $\Delta \mathrm{G}_{\text {solv }}$ from FEP/MC rather than from IEF-PCM is considered and the relative stability of the conformer/tautomer preferred by IEF-PCM further increases. Even the limited number of FEP/MC calculations pointed out significant deviations from the IEF-PCM predicted $\Delta \mathrm{G}_{\text {solv }}$, mainly in aqueous solution. The difference may be attributed to the different appreciation of the solute-water hydrogen bonds by the two methods. In the absence of experimental data in the present case, one cannot decide, which method of $\Delta \mathrm{G}_{\text {solv }}$ estimation would result in quantitatively more correct $\Delta \mathrm{G}^{\mathrm{s}}$ tot. Former studies $[16,24]$ proved that both methods could predict solvent compositions in fairly good accord with experimental data at least for the major components (e.g., gauche or trans), thus the favorable method for the calculation may also depend on the system itself.

The effect of the first-shell water on the relative conformer energies have been studied in the supermolecule/continuum solvent approximation. In the s-cis solute conformations of the tetrahydrate supermolecules, water-water hydrogen bonds are formed, which make an additional stabilization for the tetrahydate. An analysis pointed out that this energy result is a consequence of the consideration of a limited number of waters. By application of reasonable corrections, $\Delta \mathrm{E}^{\mathrm{s}}$ int $+\Delta \mathrm{G}_{\text {solv }}$ energies were obtained close to the values, which were calculated for pure solutes in water by IEF-PCM. Explicit water molecules in the supermolecule do not form water-water bond(s) in the transition state through the rotation about the central $\mathrm{C}-\mathrm{C}$ bond and the decrease of barrier is small compared to the calculated corresponding value for a pure solute placed in the solvent cavity. 
For the less stable species, the tautomerization routes of a ketene or an imino-ketene form to a DSD structure were followed and the possible role of the solvents in these processes was discussed. A proposed mechanism utilizing the water-catalyzed double proton-relay in CCNH anti to syn transformations was outlined by considering the intermolecular hydrogen bond structure in tetrahydates. Solution structure characteristics, solute-solvent hydrogen-bond patterns derived on the basis of Monte Carlo simulations are in conformity with the proposed mechanism. No clear answer could be given, however, concerning the possible catalytic effect of dichloromethane through proton transfers. Solute dimerization in this solvent does not facilitate a double proton-relay. Even the possibility was raised that the kinetic control regulates the tautomerism in an absolute water-free non-protic solvent and maintains species of high relative free energy.

Changes of the solute atom coordination numbers by the first-hydration-shell water atoms upon conformational/tautomeric transformations were analyzed for all composition groups. Hydration of the carbonyl oxygen in $\mathrm{O}=\mathrm{CH}-\mathrm{CH}=\mathrm{NH}$ is less favorable in its $s$-cis conformation with an intramolecular hydrogen bond (7, CCNH syn) and in the amino ketene tautomer (9) than in conformations with $\mathrm{CCNH}$ anti moieties $(5,8)$. The $\mathrm{NH}$ groups are differently open to hydration for the $\mathrm{NH}=\mathrm{CH}-\mathrm{CH}=\mathrm{NH}$ conformers. There is an intramolecular hydrogen bond in the $s$-cis/CCNH/syn form (13), which hinders remarkably the formations of $\mathrm{N} \ldots \mathrm{H}_{\mathrm{w}}-\mathrm{O}_{\mathrm{w}}$ and $\mathrm{N}-\mathrm{H} \ldots \mathrm{O}_{\mathrm{w}}$ hydrogen bonds in the indicated domain.

For systems including nearby, possibly interacting hydrogen-bonding sites, special molecular mechanics parameterization is needed. To this aim, proper determination of the molecular geometries and relative free energies for conformers/tautomers is required in condensed phase. Application of high-level theoretical methods is necessary for calculating correct relative internal free energies and good estimation of the relative solvation free energy is essential, as well. Regarding this latter issue, the question is whether $\Delta \mathrm{G}_{\text {solv }}$ should be calculated in a polarizable continuum solvent approximation or by utilizing the free energy perturbation method applied for solutions with explicit solvent models. Although the problem is known for a long time, its reassuring resolution has not been possible mainly due to the lack of a large number and reliable experimental studies determining in-solution equilibrium compositions including fractions for minor components, as well.

\section{Supplementary Materials}

Supplementary materials can be found at http://www.mdpi.com/1422-0067/16/05/10767/s1.

It is available for the major optimized geometric parameters and dipole moments in the gas phase and in the two solvents (Table S1 and Figure S1a-d).

\section{Acknowledgments}

The author thanks the Ohio Supercomputer Center for the granted computer time.

\section{Conflicts of Interest}

The author declares no conflict of interest. 


\section{References}

1. Nagy, P.I.; Sarver, J.G. Theoretical conformational analysis for chain systems with two conjugated double bonds in the gas phase and in solution. Comput. Theor. Chem. 2014, 1033, 43-51.

2. Houjou, H.; Shingai, H.; Yagi, K.; Yoshikawa, I.; Araki. K. Mutual interference between intramolecular proton transfer sites through the adjoining $\tilde{A} \hat{A}$-conjugated system in Schiff bases of double-headed, fused salicylaldehydes. J. Org. Chem. 2013, 78, 9021-9031.

3. Sammour, A.; Selim, M.I.B.; Nour Eldeen, M.M. Condensation of unsaturated Schiff bases with ethyl acetoacetate, diethyl malonate, and acetylacetone. J. Prakt. Chem. 1972, 314, 139-144.

4. Pollack, R.M.; Kayser, R.H.; Damewood, J.R., Jr. The effect of solvent on intramolecular general base catalysis in the hydrolysis of $\alpha, \beta$-unsaturated Schiff bases. J. Am. Chem. Soc. 1977, 99, 8232-8237.

5. Ittel, S.D.; Johnson, L.K.; Brookhart, M. Late-metal catalysts for ethylene homo- and copolymerization. Chem. Rev. 2000, 100, 1169-1203.

6. Exner, O.; Kliegman, J.M. The dipole moments and conformations of 1,2-diimines. J. Org. Chem. 1972, 36, 2014-2015.

7. Katritzky, A.R.; Hall, C.D.; El-Gendy, B.; Draghici, B. Tautomeris in drug discovery. J. Comput. Aided Mol. Des. 2010, 24, 475-484.

8. Bach, R.D.; Wolber, G.J. Theoretical analysis of the barrier to nitrogen inversion in $N$-fluoroformimine and formaldoxime. J. Org. Chem. 1982, 47, 245-248.

9. Tsuchida, N.; Yamabe, S. Paths of tautomerization between hydroxypyridines and pyridones. J. Phys. Chem. A 2005, 109, 1974-1980.

10. Nagy, P.I. The syn-anti equilibrium for the $-\mathrm{COOH}$ group reinvestigated. Theoretical conformation analysis for acetic acid in the gas phase and in solution. Comput. Theor. Chem. 2013, 1022, 59-69.

11. Guruge, A.M.; Dissanayake, D.P. Ab initio study on transition states of formohydroxamic acid tautomerization in the presence of water molecules. Comput. Theor. Chem. 2014, 1032, 50-55.

12. Allen, A.D.; Tidwell, T.T. Ketenes and other cumulenes as reactive intermediates. Chem. Rev. 2013, 113, 7287-7342.

13. Cramer, C.J.; Truhlar, D.G. Correlation and solvation effects on heterocyclic equilibria in aqueous solution. J. Am. Chem. Soc. 1993, 115, 8810-8817.

14. Wiberg, K.B.; Wong, M.W. Solvent effects. 4. Effect of solvent on the E/Z energy difference for methyl formate and methyl acetate. J. Am. Chem. Soc. 1993, 115, 1078-1084.

15. Cao, M.; Teppen, B.J.; Miller, D.M.; Pranata, J.; Schafer, L. Tautomeric equilibria of 3-hydroxypyrazole in the gas phase and in solution: A theoretical study combining ab initio quantum mechanics and Monte Carlo simulation methods. J. Phys. Chem. 1994, 98, 11353-11361.

16. Cramer, C.J.; Truhlar, D.G. Quantum chemical conformational analysis of 1,2-ethanediol: Correlation and solvation effects on the tendency to form internal hydrogen bonds in the gas phase and in aqueous solution. J. Am. Chem. Soc. 1994, 116, 3892-3900.

17. Lammertsma, K.; Prasad, V.P. Imine-Enamine tautomerism. J. Am. Chem. Soc. 1994, 116, 642-650. 
18. Tortonda, F.R.; Silla, E.; Tuñón, I.; Rinaldi, D.; Ruiz-López, M.F. Intramolecular proton transfer of serine in aqueous solution. Mechanism and energetics. Theor. Chem. Acc. 2000, 104, 89-95.

19. Long. J.A.; Harris, N.J.; Lammertsma, K. Formaldehyde oxime-Nitrosomethane tautomerism. J. Org. Chem. 2001, 66, 6762-6767.

20. Raczyńska, E.D.; Darowska, M.; Cyrański, M.K.; Makowski, M.; Rudka, T.; Gal, J.-F.; Maria, P.-C. Ab initio study of tautomerism and of basicity center preference in histamine, from gas phase to solution-Comparison with experimental data (gas phase, solution, solid state). J. Phys. Org. Chem. 2003, 16, 783-796.

21. Rejnek, J.; Hanus, M.; Kabeláč, M.; Ryjáček, F.; Hobza, P. Correlated ab initio study of nucleic acid bases and their tautomers in the gas phase, in a microhydrated environment and in aqueous solution. Part 4 Uracil and thymine. Phys. Chem. Chem. Phys. 2005, 7, 2006-2017.

22. Nagy, P.I. Theoretical studies of the solvent effect on the conformation of the HO-C-C-X $\left(\mathrm{X}=\mathrm{F}, \mathrm{NH}_{2}, \mathrm{NO}_{2}\right.$ ) moiety with competing intra- and intermolecular hydrogen bonds. J. Phys. Chem. A 2012, 116, 7726-7741.

23. Nagy, P.I. Theoretical study of the gauche-trans equilibrium with and without an intramolecular hydrogen bond for ${ }^{+} \mathrm{H}_{3} \mathrm{NCH}_{2} \mathrm{CH}_{2} \mathrm{X}$ systems $\left(\mathrm{X}=\mathrm{OH}, \mathrm{NH}_{2}, \mathrm{COO}^{-}\right)$in solution. Phys. Chem. Chem. Phys. 2012, 14, 13955-13962.

24. Nagy, P.I. Are the intramolecular O-H...F and $\mathrm{O}-\mathrm{H} . . . \mathrm{Cl}$ hydrogen bonds maintained in solution? A theoretical study. J. Phys. Chem. A 2013, 117, 2812-2826.

25. Nagy, P.I. In-solution conformational analysis of the $\mathrm{XCYCH}_{3}$ moiety for small esters and ethers with all combinations of $\mathrm{X}, \mathrm{Y}=\mathrm{O}, \mathrm{S}$. Molecules 2013, 18, 8063-8082.

26. Grimme, S. Semiempirical GGA-type density functional constructed with a long-range dispersion correction. J. Comput. Chem. 2006, 27, 1787-1799.

27. Purvis, G.D.; Bartlett, R.J. A full coupled-cluster singles and doubles model: The inclusion of the disconnected triples. J. Chem. Phys. 1982, 76, 1910-1918.

28. Raghavachari, K.; Trucks, G.W.; Pople, J.A.; Head-Gordon, M. A fifth-order perturbation comparison of electron correlation theory. Chem. Phys. Lett. 1989, 157, 479-483.

29. Penn, R.E. Microwave spectrum of 2-propene-1-imine, $\mathrm{CH}_{2}=\mathrm{CH}-\mathrm{CH}=\mathrm{NH}$. J. Mol. Spectrosc. 1978, 69, 373-382.

30. Nagy, P.I. Competing intramolecular vs. intermolecular hydrogen bonds in solution. Int. J. Mol. Sci. 2014, 15, 19562-19633.

31. Bondi, A. Van der Waals volumes and radii. J. Phys. Chem. 1964, 68, 441-451.

32. Breneman, C.M.; Wiberg, K.B. Determining atom-centered monopoles from molecular electrostatic potentials. The need for high sampling density in formamide conformational analysis. J. Comput. Chem. 1990, 11, 361-373.

33. Hobza, P.; Havlas, Z. Blue-shifting hydrogen bonds. Chem. Rev. 2000, 100, 4253-4264.

34. Hargittai, I.; Seip, R. On the molecular structure of $N, N^{\prime}$-di-t-butyl-1,2-ethanediimine, $\left(\mathrm{CH}_{3}\right)_{3} \mathrm{CN}=\mathrm{CHCH}=\mathrm{NC}\left(\mathrm{CH}_{3}\right)_{3}$, as studied by gas electron diffraction. Acta Chem. Scand. A 1976, $30,540-546$.

35. Mills, P.; Jentz, D.; Celio, H.; Trenary, M. Formation of $\mu 2, \eta^{2}$-diaminoethylene $\left(\mathrm{H}_{2} \mathrm{NCCNH}_{2}\right)$ from cyanogen $\left(\mathrm{C}_{2} \mathrm{~N}_{2}\right)$ and hydrogen on $\mathrm{Pt}(111)$ : Characterization of a diiminium surface species. J. Am. Chem. Soc. 1996, 118, 6524-6525. 
36. Alagona, G.; Ghio, C.; Nagy, P.I. Theoretical studies on the effects of methods and parameterization on the calculated free energy of hydration for small molecules. Int. J. Quant. Chem. 2004, 99, 161-178.

37. Jorgensen, W.L.; Chandrasekhar, J.; Madura, J.D.; Impey, R.W.; Klein, M.L. Comparison of simple potential functions for simulating liquid water. J. Chem. Phys. 1983, 79, 926-935.

38. Zwanzig, R.W. High-temperature equation of state by a perturbation method. I. Nonpolar gases. J. Chem. Phys. 1954, 22, 1420-1426.

39. Jorgensen, W.L.; Ravimohan, C. Monte Carlo simulation of differences in free energies of hydration. J. Chem. Phys. 1985, 83, 3050-3054.

40. Cramer, C.C. Essentials of Computational Chemistry: Theories and Models, 2nd ed.; John Wiley \& Sons, Ltd.: Chichester, UK, 2004; pp. 85-86.

41. Rice, C.A.; Borho, N.; Suhm, M.A. Dimerization of pyrazole in slit jet expansions. Z. Phys. Chem. 2005, 219, 379-388.

42. Ciccotti, G.; Ferrario, M.; Hynes, J.T.; Kapral, R. Constrained molecular dynamics and the mean potential for an ion pair in a polar solvent. Chem. Phys. Lett. 1989, 129, 241-251.

43. Frisch, M.J.; Trucks, G.W.; Schlegel, J.B.; Scuseria, G.E.; Robb, M.A.; Cheeseman, J.R.; Gaussian 09, Revision C.01; Gaussian, Inc.: Wallingford, CT, USA, 2010.

44. Dunning, T.H., Jr. Gaussian basis sets for use in correlated molecular calculations. I. The atoms boron through neon and hydrogen. J. Chem. Phys. 1989, 90, 1007-1023.

45. Kendall, R.A.; Dunning, T.H., Jr.; Harrison, R.J. Electron affinities of the first-row atoms revisited. Systematic basis sets and wave functions. J. Chem. Phys. 1992, 96, 6796-6806.

46. Peterson, K.A. Gaussian basis sets exhibiting systematic convergence to the complete basis set limit. Annu. Rep. Comput. Chem. 2007, 3, 195-206.

47. Miertus, S.; Scrocco, E.; Tomasi, J. Electrostatic interaction of a solute with a continuum. A direct utilization of ab intio molecular potentials for the prevision of solvent effects. Chem. Phys. 1981, $55,117-129$.

48. Tomasi, J.; Mennucci, B.; Cammi, R. Quantum mechanical continuum solvation models. Chem. Rev. 2005, 105, 2999-3094.

49. McQuarrie, D.A. Statistical Mechanics; University Science Books: Sausalito, CA, USA, 2000.

50. Nagy, P.I.; Alagona, G.; Ghio, C. Theoretical investigation of tautomeric equilibria for isonicotinic acid, 4-pyridone, and acetylacetone in vacuo and in solution. J. Chem. Theory Comput. 2007, 3, 1249-1266.

51. Hobza, P. Theoretical studies of hydrogen bonding. Annu. Rep. Prog. Chem. Sect. C 2004, 100, 3-27.

52. Helgaker, T.; Klopper, W.; Koch, H.; Noga, J. Basis-set convergence of correlated calculations on water. J. Chem. Phys. 1997, 106, 9639-9646.

53. Jorgensen, W.L.; Madura, J.D. Quantum and statistical mechanical studies of liquids. 25. Solvation and conformation of methanol in water. J. Am. Chem. Soc. 1983, 105, 1407-1413.

54. Jorgensen, W.L.; Swenson, C.J. Optimized intermolecular potential functions for amides and peptides. Hydration of amides. J. Am. Chem. Soc. 1985, 107, 1489-1496.

55. Jorgensen, W.L.; Gao, J. Monte Carlo simulations of the hydration of ammonium and carboxylate ions. J. Phys. Chem. 1986, 90, 2174-2182. 
56. Jorgensen W.L. BOSS, Version 4.8 Biochemical and Organic Simulation System User's Manual; Yale University: New Haven, CT, USA, 2007.

57. Jorgensen, W.L.; Maxwell, D.S.; Tirado-Rives, J. Development and testing of the OPLS all-atom force field on conformational energetics and properties of organic liquids. J. Am. Chem. Soc. 1996, 118, 11225-11236.

58. Rizzo, R.C., Jorgensen, W.L. OPLS all-atom model for amines: Resolution of the amine hydration problem. J. Am. Chem. Soc. 1999, 121, 4827-4836.

59. Lim, D.; Hrovat, D.A.; Borden, W.T.; Jorgensen, W.L. Solvent effects on the ring opening of cyclopropanones to oxyallyls: A combined ab initio and Monte Carlo study. J. Am. Chem. Soc. 1994, 116, 3494-3499.

60. Ewald, P.P. Die Berechnung optischer und elektrostatischer Gitterpotentiale. Ann. Phys. 1921, $369,253-287$.

61. Allen, M.P.; Tildesley, D. Computer Simulations of Liquids; Oxford University Press: Oxford, UK, 1987.

(C) 2015 by the authors; licensee MDPI, Basel, Switzerland. This article is an open access article distributed under the terms and conditions of the Creative Commons Attribution license (http://creativecommons.org/licenses/by/4.0/). 